\title{
Dynamic consolidation of superhard materials
}

\author{
Wenbo Yang \\ Lindhurst Laboratory of Experimental Geophysics, Seismological Laboratory, California Institute \\ of Technology, Pasadena, California 91125 \\ G. M. Bond \\ Department of Materials and Metallurgical Engineering, New Mexico Institute of Mining and Technology, \\ Socorro, New Mexico 87801 \\ Hua Tan \\ Beijing Institute of Technology, P. O. Box 327, Beijing, People's Republic of China \\ Thomas J. Ahrens \\ Lindhurst Laboratory of Experimental Geophysics, Seismological Laboratory, California Institute \\ of Technology, Pasadena, California 91125 \\ G. Liu \\ Department of Materials and Metallurgical Engineering, New Mexico Institute of Mining and Technology, \\ Socorro, New Mexico 87801
}

(Received 20 May 1990; accepted 27 January 1992)

Shock consolidation experiments were conducted via flyer impact on synthetic diamond $(6-12 \mu \mathrm{m})$ and cubic boron nitride (c-BN) $(4-8 \mu \mathrm{m})$ admixed with SiC whisker (SCW), $\mathrm{Si}_{3} \mathrm{~N}_{4}$ whisker ( $\mathrm{SNW}$ ), $\mathrm{SiC}$ powder, and $\mathrm{Si}$ powder contained in stainless steel capsules under the shock pressure range of 10-30 GPa. Scanning electron microscopy and transmission electron microscopy imaging of the samples revealed no plastic deformation or melting of diamond and virtually no deformation of c-BN, whereas the SCW and SNW were extensively melted and recrystallized into bundle-shaped crystallites. In contrast, $\mathrm{SiC}$ powder mixed with diamond was also melted but demonstrated equant grain growth. A new method to calculate the shock temperature and melt fraction is formulated on the basis of Milewski's sphere-rod packing data. The new method assigns excess bulk volume to the zone around whiskers and yields a better description of the energy deposition mechanism of the consolidation of powder-whisker systems. Some of the experiments employed Sawaoka's post-shock annealing technique, in which the sample is sandwiched between two layers of a mixture of titanium powder plus carbon. Very well consolidated samples were obtained with post-shock heating under shock pressures of only about $11 \mathrm{GPa}$. Micro-Vickers hardness values up to $27 \mathrm{GPa}$ were obtained for c-BN plus SCW at a low impact velocity of $1.45 \mathrm{~km} / \mathrm{s}$ with post-shock heating. This hardness is similar to that obtained at a higher impact velocity of $1.95 \mathrm{~km} / \mathrm{s}$ without post-shock heating. To understand the post-shock heating process, one-dimensional time dependent temperature profile calculations were conducted for the sample and $\mathrm{Ti}+\mathrm{C}$ layers. Post-shock heating appears to be very important in the consolidation of powder and whisker admixture. The calculated optimum $\mathrm{Ti}+\mathrm{C}$ thickness is about $0.8-1.7 \mathrm{~mm}$ at a porosity of $40 \%$ for a typical sample thickness of $2 \mathrm{~mm}$. The heating and cooling time is a few milliseconds. Good compacts with micro-Vickers hardness values up to $28 \mathrm{GPa}$ were also obtained upon shock consolidation of diamond plus Si admixtures.

\section{INTRODUCTION}

Dynamic consolidation of such superhard materials as diamond and (diamond-structured) cubic boron nitride (c-BN) initially in powder form with grain sizes in the range of $10-50 \mu \mathrm{m}$ shows some promise as a potential process for obtaining large quantities of technologically useful compacts. Single crystal powders of diamond are available from natural and synthetic sources, ${ }^{1}$ whereas c-BN single crystal powders are produced for abrasive applications with static high-pressure techniques. ${ }^{2}$ Recently several studies have been conducted in which single crystal powders, initially in the range of $60-70 \%$ of crystal density, have been consolidated to nearly crystal density by driving initial shocks of amplitudes in the range of $30 \mathrm{GPa}$ into sample containers within steel recovery fixtures. These shock pressures have been generated with both the impact of flyer plates accelerated with propellant and high explosive systems. ${ }^{3,4}$ In the 
case of diamond, scanning electron microscopy (SEM) images indicated that shock-induced interparticle bonding appears to result from local melting. Interparticle sliding upon compaction is suggested to produce this melting. Transmission electron microscopy (TEM) of shock consolidated diamond ${ }^{5}$ demonstrates that this apparently melted material transforms, in part, to very fine polycrystalline diamond, an amorphous carbon phase, and graphite upon unloading and cooling. The presence of the graphite phase probably prevents this material from demonstrating exceptional small-scale strength in Vickers hardness tests. In contrast, single crystal c-BN compaction ${ }^{6}$ requires considerably higher shock pressures $(33-77 \mathrm{GPa})$ to consolidate to nearly crystal density. This material demonstrates an impressive hardness of $50 \mathrm{GPa}$ approaching that of single crystal c-BN (66-75 GPa). The consolidation mechanism in these experiments is not known although surface melting may also be occurring. Because of the irregularity and brittleness of the single crystals used in shock loading experiments, sound bonding between grains is not easy to obtain as the crystals tend to crack rather than change their shape plastically to fill the space between them.

Recently, Tan and Ahrens ${ }^{7}$ reported the c-BN admixed with either $\mathrm{Si}_{3} \mathrm{~N}_{4}(\mathrm{SNW})$ or $\mathrm{SiC}(\mathrm{SCW})$ whiskers formed hard uniform compacts upon shock compression to $22-23 \mathrm{GPa}$, starting with mixtures that were $\sim 70 \%$ of crystal density and contained 15 to $20 \%$ of whisker materials. Micro-Vickers hardness values as high as $50 \mathrm{GPa}$ were obtained for c-BN plus SNW mixture.

In the present study this work is extended to include studies of shock consolidation of diamond admixtures with SNW, SCW, SiC powder, and Si powder. Samples were examined with SEM. In addition, a limited number of samples were studied by TEM. The TEM studies provided insight into the physics of consolidation mechanism of whisker-cubic crystal mixtures and motivated a modification of previous thermodynamic modeling methodology for shock consolidation. A new calculation model of consolidation of cubic crystal-whisker mixtures is presented and a series of revised thermodynamic calculations of the shock states achieved in the cubic crystal and whisker phases are conducted with this formulation. Finally, since many of our experiments employed layers of $\mathrm{Ti}+\mathrm{C}$ surrounding our samples (first suggested by Sawaoka et al., 1988), we have developed a thermal model to describe the post-shock thermal annealing that takes place in the assembly.

\section{EXPERIMENTAL METHOD}

In addition to the $\mathrm{SCW}, \mathrm{c}-\mathrm{BN}$, and $\mathrm{SNW}$ used in previous experiments, ${ }^{7}$ we employed $\beta-\mathrm{SiC}$ single crystal powder and Si single crystal powder. The $\beta-\mathrm{SiC}$ single crystal powder is a product of Ibiden Co. Ltd. This material is reported by the manufacturer to have an average crystal diameter of $0.28 \mu \mathrm{m}$. The main impurities, with a total mass of less than $1 \%$, are $\mathrm{Al}, \mathrm{Fe}, \mathrm{SiO}_{2}, \mathrm{C}$, and $\mathrm{H}_{2} \mathrm{O}$. The Si powder is commercially obtained with sizes of -325 mesh (less than $44 \mu \mathrm{m}$ ). The impurities are also less than $1 \mathrm{wt} \%$.

Two series of new experiments were conducted. The first series of experiments, which we carried out with a $20 \mathrm{~mm}$ propellant gun, included diamond powder mixed with SCW, SNW, SiC powder, or Si powder in different mass ratios and initial porosities. Samples of pure diamond and SCW were also shock compressed to provide a comparison to the admixtures. The second series of experiments was conducted with a $40 \mathrm{~mm}$ propellant gun. In these experiments, following the idea of Sawaoka, ${ }^{8}$ we consolidated the diamond (or c-BN) and SCW mixtures initially $2-3 \mathrm{~mm}$ thick, which were sandwiched by a $0.8-1.5 \mathrm{~mm}$ thick titanium and carbon black mixture. The purpose of the metallic titaniumcarbon mixture is to provide a post-shock heat source to anneal the sample. The thermodynamics of this reaction and resultant heat flow are described in Sec. VI.

The sample was pressed into a stainless steel capsule and under a vacuum of about $30 \mu \mathrm{m}$. A tantalum flyer plate was used to impact the sample assembly. The thicknesses of these plates for the $20 \mathrm{~mm}$ gun and $40 \mathrm{~mm}$ gun were $1.5 \mathrm{~mm}$ and $2.6 \mathrm{~mm}$, respectively. The recovery method with momentum trap techniques, as previously described, ${ }^{7}$ was used.

\section{RESULTS}

\section{A. Diamond powder plus SNW}

Our results are summarized in Table I. The estimated shock pressures in these experiments are about $25 \mathrm{GPa}$. Of the five shots, four sample assemblies exploded, leaving a hole in the center of the recovered Ta flyer plate. We infer that these explosions result from the expansion of $\mathrm{N}_{2}$ gas produced by the reaction

$$
3 \mathrm{C}+\mathrm{Si}_{3} \mathrm{~N}_{4}=3 \mathrm{SiC}+2 \mathrm{~N}_{2}
$$

At ambient pressure and temperatures higher than $1626 \mathrm{~K}$, the calculated Gibbs formation energy difference, $\Delta G$, has negative values (Fig. 1). The Gibbs formation energy at high temperature of $\mathrm{SiC}$ and $\mathrm{Si}_{3} \mathrm{~N}_{4}$ is obtained from Ref. 9, and the Gibbs formation energy of diamond is from Ref. 30. According to our new calculation method, the SNW in these experiments will have a post-shock temperature of $2173 \mathrm{~K}$ (melting point) and about $80 \%$ of them will be shock melted.

The SEM image of a sample piece recovered from shot 961 is shown in Fig. 2. It demonstrates that the SNW has melted but does not indicate strong bonding between diamond particles although good consolidation can be seen in the very well mixed region. The fracture 
TABLE I. Diamond plus silicon nitride whisker (SNW) shock consolidation experiments.

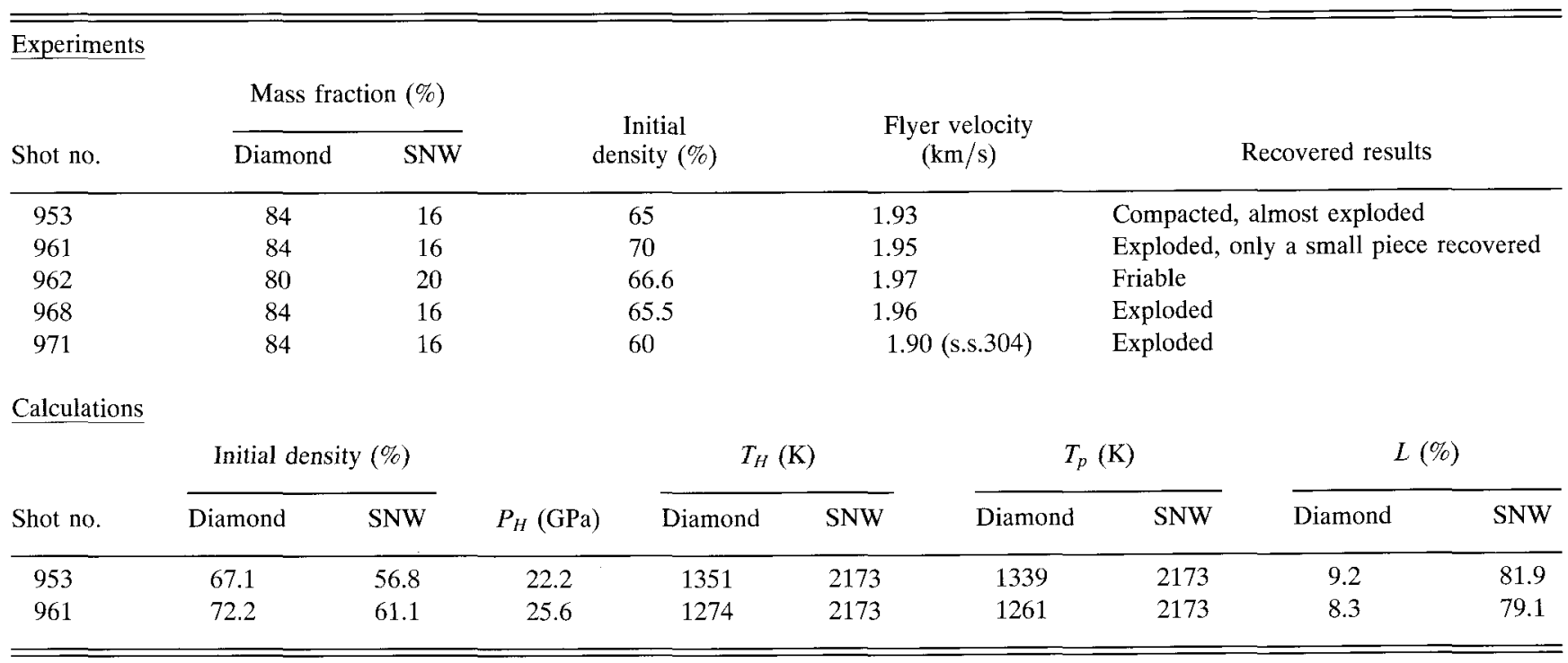

of individual diamond crystals can be seen clearly. A better consolidated sample might have been obtained if the content of SNW had been increased and the sample had been consolidated under a lower pressure.

\section{B. Diamond plus SCW}

Most samples from these experiments were successfully recovered (Table II). Two rather hard samples were obtained from shots 969 and 973 with 20 and 25 wt. \% SCW, respectively. A very well consolidated sample was obtained from shot 1028 (Fig. 3). For this shot, we added $30 \mathrm{wt} \% \mathrm{SCW}$ to the diamond powder and expected that the additional SCW would protect the diamond grains from being fractured. This shot provided the best compact achieved with diamond. However, the SEM images show that the diamond in all the present experiments is seriously fractured. Although the

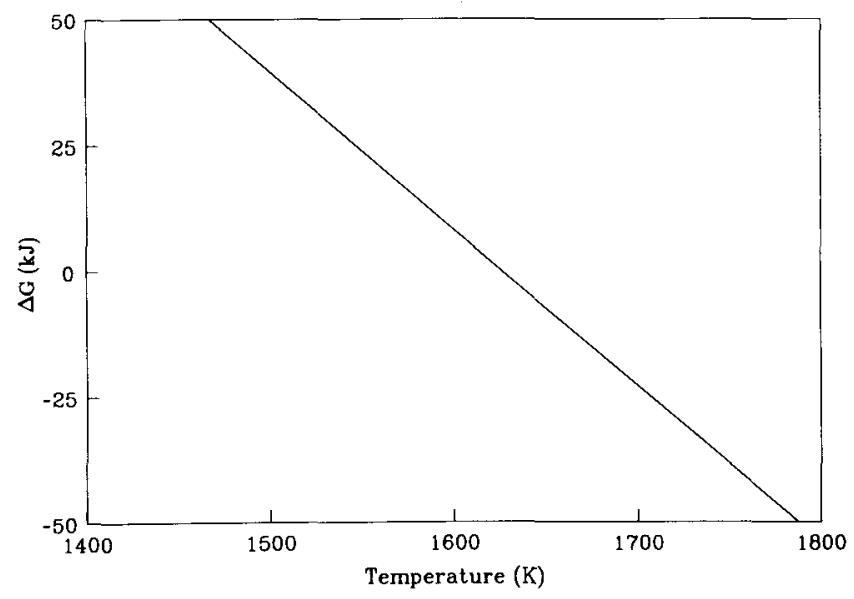

FIG. 1. Calculated Gibbs formation energy difference $\Delta G$ vs temperature of the reaction $3 \mathrm{C}+\mathrm{Si}_{3} \mathrm{~N}_{4} \rightarrow 3 \mathrm{SiC}+2 \mathrm{~N}_{2} \uparrow$. fusion bonding between diamond particles in some shots appears to be incomplete, the SEM images show that the SCW material is completely shock melted in all the experiments. In order to determine whether the $\mathrm{Al}_{2} \mathrm{O}_{3}$ shim was critical to the achievement of high quality compacts, we conducted shot 1007 (Table II) without an $\mathrm{Al}_{2} \mathrm{O}_{3}$ shim at the impact end of the sample. No evidence of consolidation was obtained from the SEM image for this experiment. The lack of consolidation is thought to result from the metallic spray from the sample container which contaminates the diamond plus SCW sample.

Although the fusion bonding between diamond particles in some shots appears to be incomplete, the SEM images indicate that the SCW material is completely shock melted and has flowed between the diamond particles.

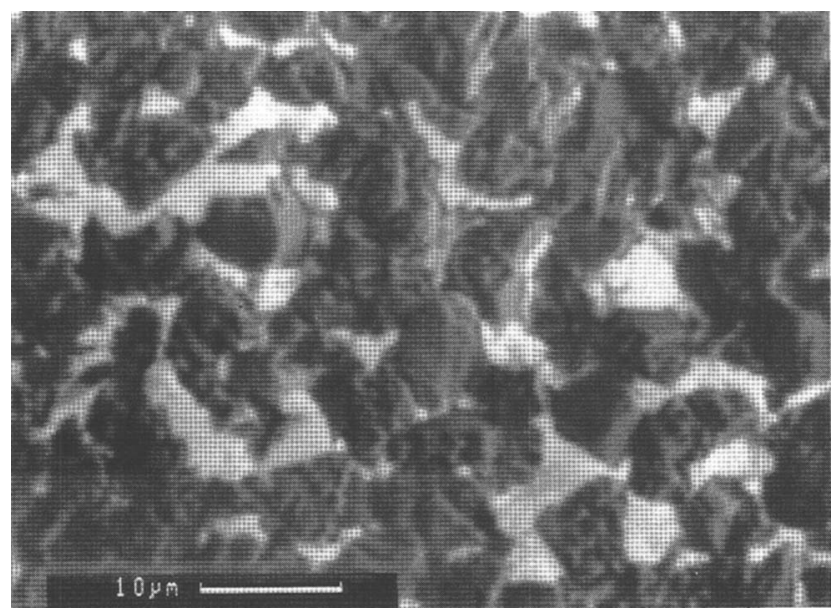

FIG. 2. SEM image of diamond plus SNW. Shot 961. The lightcolored phase is silicon nitride whisker (SNW). 
TABLE II. Diamond plus silicon carbide whisker (SCW) shock consolidation experiments.

\begin{tabular}{|c|c|c|c|c|c|c|c|c|c|c|}
\hline \multicolumn{11}{|c|}{ Experiments } \\
\hline \multirow[b]{2}{*}{ Shot no. } & \multicolumn{3}{|c|}{ Mass fraction (\%) } & \multirow{2}{*}{\multicolumn{2}{|c|}{$\begin{array}{c}\text { Initial } \\
\text { density }(\%)\end{array}$}} & \multirow{2}{*}{$\begin{array}{l}\text { Flyer velocity } \\
\qquad(\mathrm{km} / \mathrm{s})\end{array}$} & & \multirow{2}{*}{\multicolumn{3}{|c|}{ Recovered results }} \\
\hline & \multicolumn{2}{|l|}{ Diamond } & $\mathrm{SCW}$ & & & & & & & \\
\hline 966 & 80 & & 20 & 70 & & 1.99 & Friable & & & \\
\hline 969 & 80 & & 20 & 60 & & 1.90 & Compr & , hardne & teel, cracks & \\
\hline 970 & 100 & & & 55 & & 1.90 (s.s.304) & Friable & & & \\
\hline 973 & 75 & & 25 & 60 & & 2.00 & Conso & ed, hard & $\mathrm{WC}$, nume & cracks \\
\hline 1007 & 75 & & 25 & 60 & & 1.85 & Uncon & & & \\
\hline 1028 & 70 & & 30 & 60 & & 1.95 & Conso & ed, scrat & pphire & \\
\hline \multicolumn{11}{|c|}{ Calculations } \\
\hline & \multicolumn{2}{|c|}{ Initial density $\%$} & & & \multicolumn{2}{|c|}{$T_{H}(\mathrm{~K})$} & \multicolumn{2}{|c|}{$T_{p}(\mathrm{~K})$} & \multicolumn{2}{|c|}{$L(\%)$} \\
\hline Shot no. & Diamond & $\mathrm{SCW}$ & & $P_{H}(\mathrm{GPa})$ & Diamond & $\mathrm{SCW}$ & Diamond & SCW & Diamond & $\mathrm{SCW}$ \\
\hline 969 & 63.7 & 49.7 & & 19.0 & 1344 & 2953 & 1335 & 2894 & 9.1 & 37.7 \\
\hline 973 & 66.8 & 47.0 & & 20.7 & 1304 & 2963 & 1294 & 2963 & 8.7 & 45.8 \\
\hline 1028 & 71.4 & 44.8 & & 19.7 & 1117 & 2963 & 1109 & 2963 & 6.6 & 47.7 \\
\hline
\end{tabular}

\section{Diamond plus SiC powder and C-BN plus SiC powder}

Unlike our previous results for shock compaction of c-BN plus SCW, no consolidated sample of c-BN plus $\mathrm{SiC}$ powder mixture was obtained. The major results are listed in Table III.

Diamond plus $\mathrm{SiC}$ powder also does not consolidate with the present method and the results are considerably less successful than the diamond plus SCW experiments.

\section{Diamond plus SCW sandwiched with $\mathrm{Ti}+\mathrm{C}$}

These experiments were conducted with a $40 \mathrm{~mm}$ gun rather than a $20 \mathrm{~mm}$ gun and employed samples

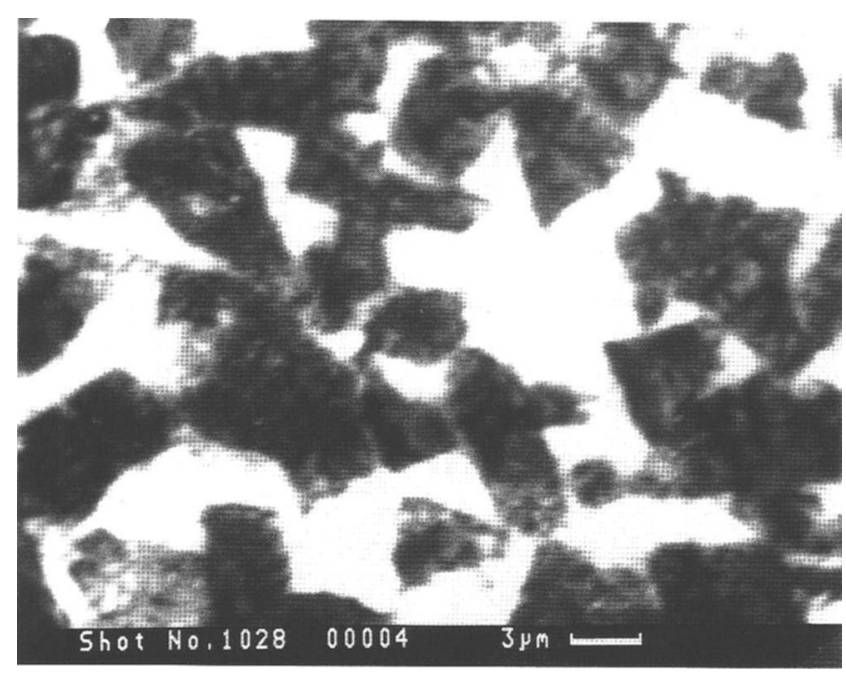

FIG. 3. SEM image of diamond plus SCW. Shot 1028 (SCW, lightcolored phase) shows very well consolidated features. The fractures of diamond (dark phase) grains can be clearly seen in the image. that contained three layers: $\mathrm{Ti}$ plus $\mathrm{C}$, diamond plus $\mathrm{SCW}$, and $\mathrm{Ti}$ plus $\mathrm{C}$. We chose a stoichiometric ratio for $\mathrm{Ti}$ to $\mathrm{C}$ equal to that in $\mathrm{TiC}$ of 3.99 to 1 . The major results of the experiments are presented in Table IV. Notably, the impact velocity of the $2.6 \mathrm{~mm}$ thick Ta flyer plate is much lower than those used in $20 \mathrm{~mm}$ gun experiments (see Table II) and a longer shock duration is employed. The recovered samples indicated a wellconsolidated appearance with very few cracks. MicroVickers hardness tests were conducted and resulted in a hardness of about $10 \mathrm{GPa}$. SEM images (Fig. 4) demonstrate that the whisker materials are not very well dispersed in the diamond powder and there are cracks in the SCW-rich zones. Moreover, the diamond powders, although well consolidated in what appears to be melted $\mathrm{SCW}$, are unexpectedly severely cracked. Both the lack of ideal diamond-SCW dispersion and excessive diamond cracking probably interfere with obtaining optimum consolidation.

\section{E. C-BN plus SCW sandwiched with $\mathrm{Ti}+\mathrm{C}$}

Two shots were fired and the results are listed in Table V. The $\mathrm{Ti}+\mathrm{C}$ layer is $\sim 0.8 \mathrm{~mm}$ thick and the impact velocity is 1.35 to $1.45 \mathrm{~km} / \mathrm{s}$ in these shots. The recovered sample of shot 787 is very well consolidated. The bonding between c-BN particles by the SCW texture is very sound. This sample is very hard and tough and the sample container was opened via surface grinding. The silicon carbide grinding wheel sparked brilliantly whenever it contacted the sample. A tungsten carbide probe deposited material onto the sample surface rather than scratching the sample. These observations are compatible with our previous shock compaction results 
TABLE III. Cubic boron nitride (c-BN) plus SiC powder shock consolidation experiments.

\begin{tabular}{rlcccc}
\hline & \multicolumn{2}{c}{ Mass fraction $(\%)$} & & $\begin{array}{c}\text { Flyer velocity } \\
(\mathrm{km} / \mathrm{s})\end{array}$ & Recovered results \\
\cline { 2 - 5 } Shot no. & c-BN & SiC & density $(\%)$ & 1.89 & Friable \\
\hline 980 & 80 & 20 & 70 & 1.96 & Hard, many cracks \\
982 & 80 & 20 & 60 & 2.0 & Recovered a snall friable piece \\
983 & 75 (diamond) & 25 & 60 & 1.76 & Still powder \\
1001 & 80 & 20 & 70 & 1.56 & Still powder \\
1002 & 75 & 25 & 70 & 2.03 & Friable \\
1003 & 75 & 25 & 70 & & \\
\hline
\end{tabular}

TABLE IV. Diamond plus silicon carbide whisker (SCW) sandwiched with $\mathrm{Ti}+\mathrm{C}$, shock consolidation experiments.

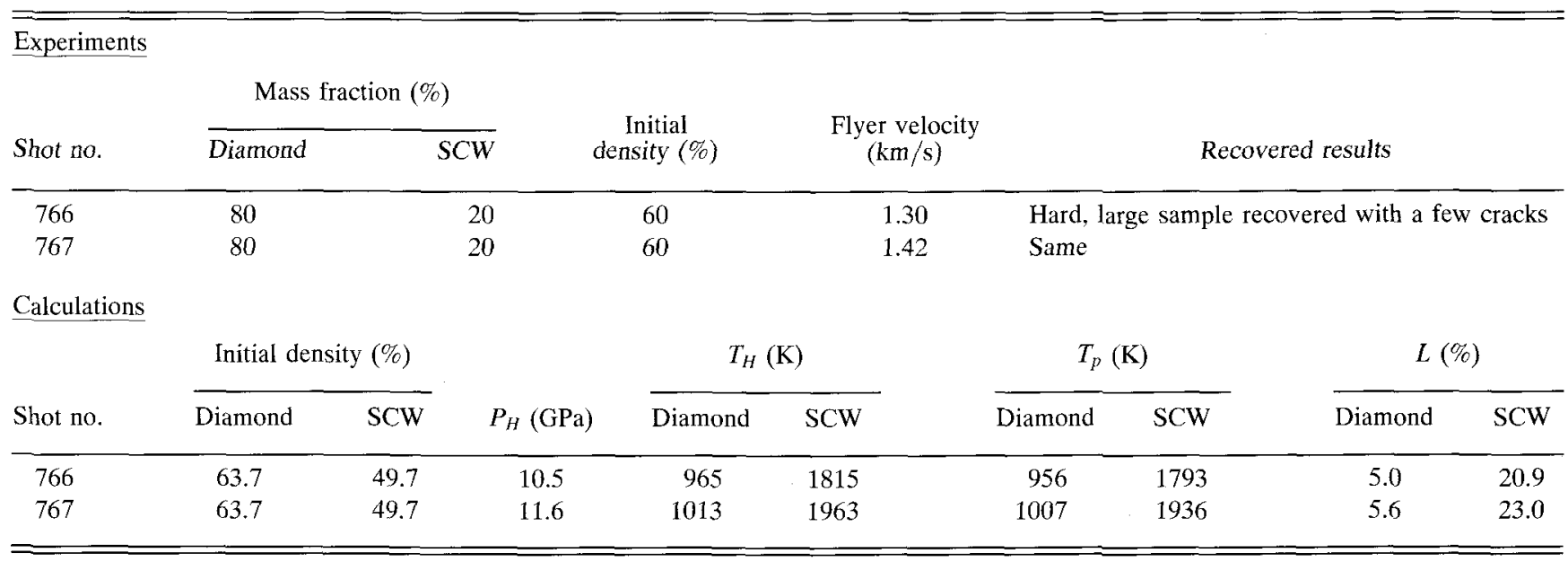

of non-sandwiched c-BN plus SCW mixture performed with a $20 \mathrm{~mm}$ gun, in which a higher impact velocity (1.95 km/s) and initial density ( $\sim 70 \%$ of crystal density) were used. Micro-Vickers hardness test shows the sample has a hardness of about $27 \mathrm{GPa}$. We also measured the sample's density and its longitudinal wave velocity. The

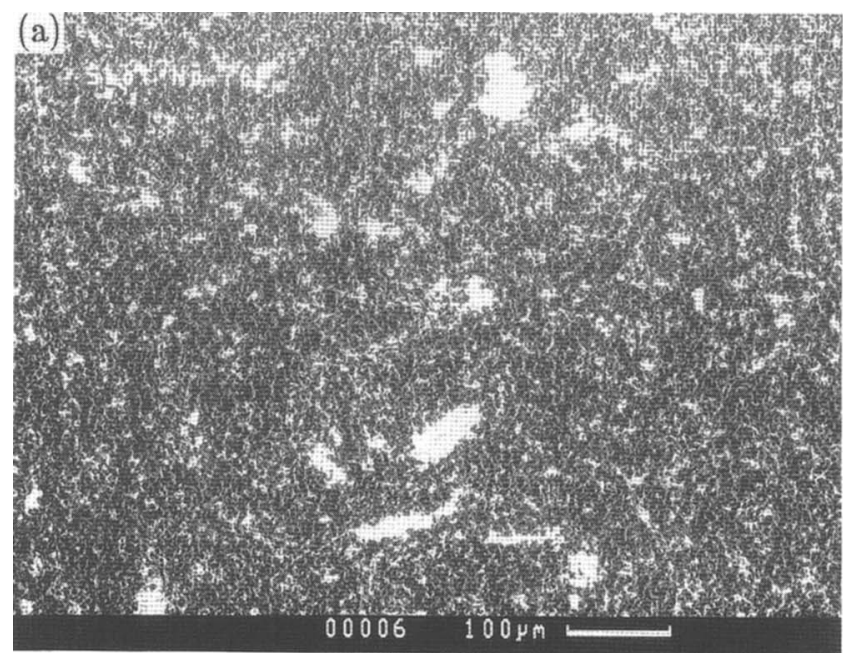

results are given in Table VI. It appears that this sample achieved the crystal density of the mixture within the stated uncertainties.

In comparison with shot 787 , the recovered sample of shot 786 shows a relatively lower hardness and less consolidation, due to the lower impact velocity. We thus

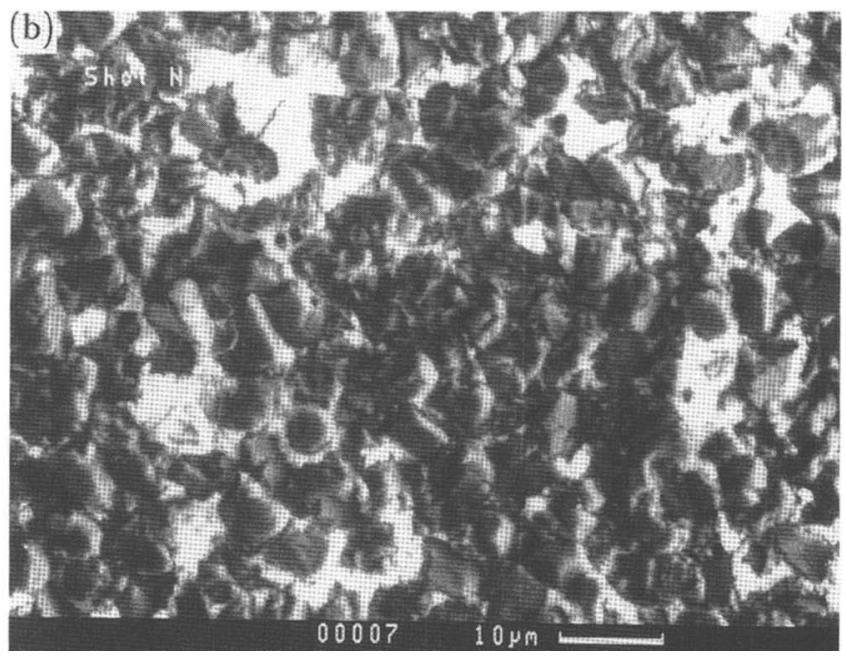

FIG. 4. SEM images of diamond plus SCW sandwiched with $\mathrm{Ti}+\mathrm{C}$. (a) and (b) show the cracks in the SCW-rich regions and the heavily pulverized diamond grains in the SCW deficient region of shot 767. 
TABLE V. Shock consolidation results, c-BN plus SCW sandwiched with Ti $+\mathrm{C}$.

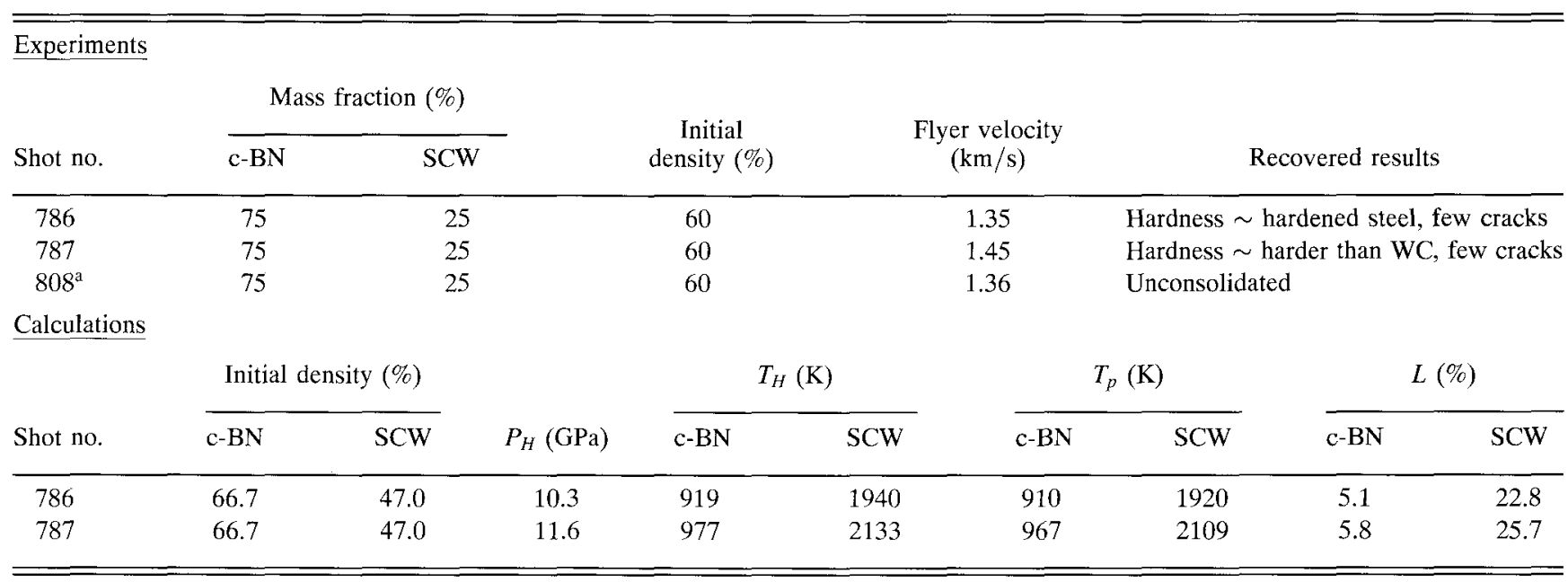

${ }^{2}$ Not sandwiched with $\mathrm{Ti}+\mathrm{C}$.

expect better consolidation with a slightly higher velocity. Radial cracks still exist in the recovered samples, which are caused by the radial stress from the side rarefaction wave after shock wave passage. We believe these cracks can be eliminated by the use of appropriate radial momentum trapping. ${ }^{10}$ Moreover, the use of starshaped flyer plates as proposed by Kumar and Clifton ${ }^{32}$ appears to be an effective tool for reducing cracking. ${ }^{33}$ Also the use of impedance matching container ${ }^{34}$ appears promising.

A SEM image is shown in Fig. 5 that demonstrates sound bonding between c-BN particles. Notably, no cracks can be seen in the c-BN crystals. This implies the $c$-BN single crystals are stronger than the man-made single crystal diamond upon shock consolidation.

\section{F. Attempted shock compaction of SCW}

Three experiments were conducted. Two of these totally failed. A third shot (shot 1004) was carried out without an $\mathrm{Al}_{2} \mathrm{O}_{3}$ shim at the impact end of the sample (Table VII).

SEM analysis of a small aliquot sample shows that these whisker materials are not compacted, and many of them still retain their original texture (Fig. 6).
Calculations employing the shock wave data in Ref. 20 show that, with an impact velocity of $1.95 \mathrm{~km} / \mathrm{s}$, the initial shock pressure for shot 1004 is about $13 \mathrm{GPa}$. This pressure may be below the Hugoniot elastic limit of SCW. Only a very small amount of deformed sample material was found in the outer part of the recovered sample.

\section{G. Diamond plus Si powder}

Five experiments were conducted (Table VIII). All of them were recovered and very hard samples were obtained. The resulting samples can scratch glass or single crystal $\mathrm{Al}_{2} \mathrm{O}_{3}$. Samples obtained from high velocity $(\sim 2.0 \mathrm{~km} / \mathrm{s})$ impacts have micro-Vickers hardnesses up to $28 \mathrm{GPa}$. A typical SEM image (Fig. 7) demonstrates that all the $\mathrm{Si}$ powders are shock melted. Very sound bonding between diamond crystals by melted $\mathrm{Si}$ can be seen. As in other experiments with synthetic diamond powders, the diamond crystals are pulverized by shock loading. Shot 807 was performed with the $40 \mathrm{~mm}$ gun and sandwiched by $\mathrm{Ti}$ plus carbon black. The impact velocity is much lower $(1.18 \mathrm{~km} / \mathrm{s})$ compared with other shots.

TABLE VI. Elastic moduli of superhard materials.

\begin{tabular}{|c|c|c|c|c|}
\hline Crystal (structure) & $\begin{array}{l}\text { Bulk modulus } \\
\text { (GPa) }\end{array}$ & $\begin{array}{c}\text { Shear modulus } \\
(\mathrm{GPa})\end{array}$ & $\begin{array}{l}\text { Density } \\
\left(\mathrm{g} / \mathrm{cm}^{3}\right)\end{array}$ & $\begin{array}{c}\text { Longitudinal } \\
\text { wave velocity } \\
(\mathrm{km} / \mathrm{s})\end{array}$ \\
\hline $\mathrm{C}$ (diamond) & 441 & 532 & 3.51 & 18.1 \\
\hline $\mathrm{BN}$-(diamond) & 369 & 445 & 3.489 & 16.6 \\
\hline SiC (zincblende) & 200 & 173 & 3.122 & 11.8 \\
\hline (Theoretical) $4: \mathrm{BN}+1: \mathrm{SiC}$ & 276 & 342 & 3.39 & 14.7 \\
\hline (Observed) $4: \mathrm{BN}+1: \mathrm{SiC}$ & & & $3.449 \pm 0.19$ & $12.27 \pm 0.58$ \\
\hline
\end{tabular}



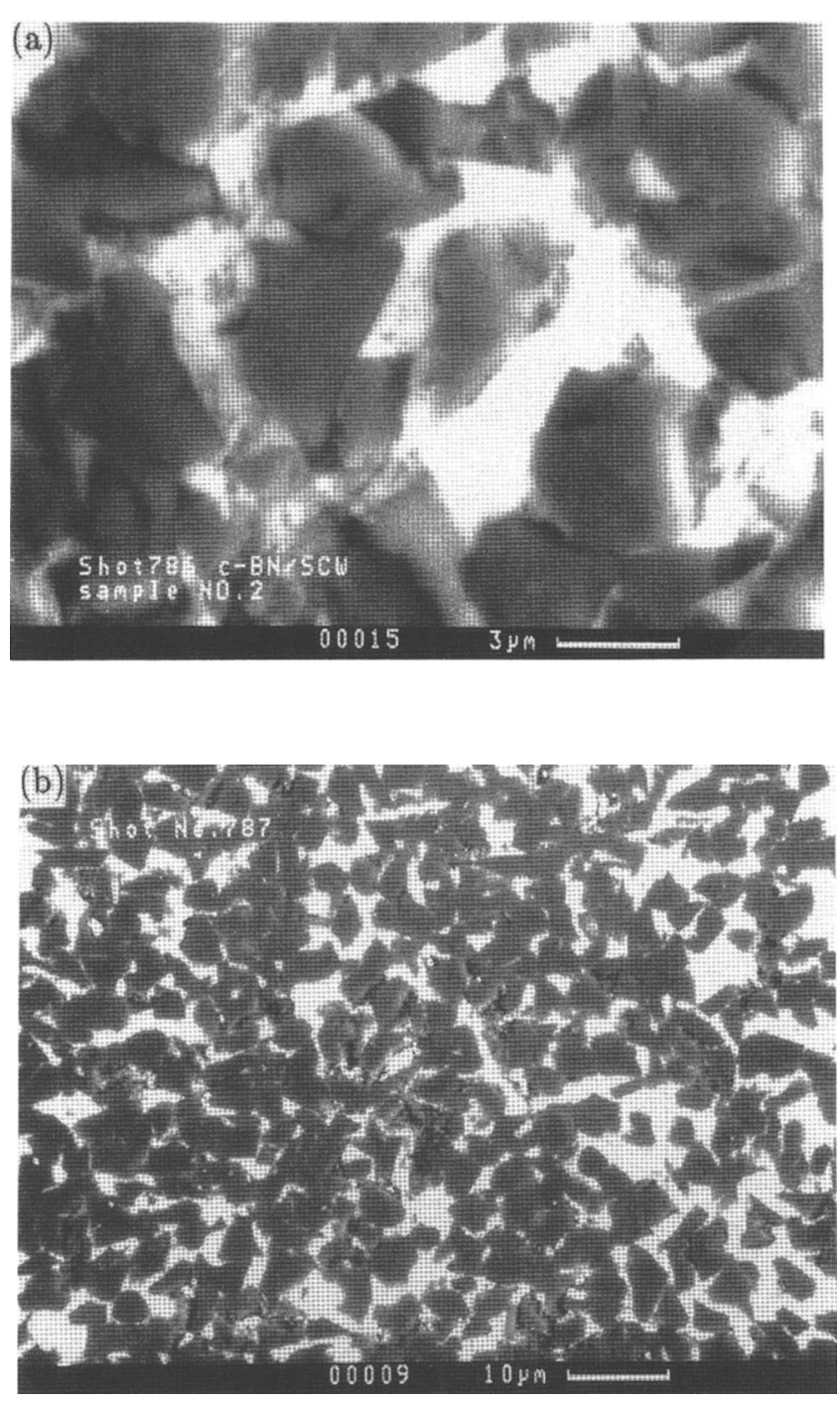

FIG. 5. SEM images of $\mathrm{c}-\mathrm{BN}$ plus SCW sandwiched with $\mathrm{Ti}+\mathrm{C}$. (a) Shot 786; (b) shows very nice texture of SCW in shot 787 . Note that no cracks can be seen in the c-BN grains.

\section{TEM RESULTS}

The major objective of the TEM study of the present samples was to determine whether the SiC whisker and powder and/or diamond had melted along the interfaces, and whether diamond-silicon carbide reactions had occurred at the interface between phases. We also expected to determine whether cracks were present be-

TABLE VII. Attempted consolidation of SCW.

\begin{tabular}{rccl}
\hline \hline Shot no. & $\begin{array}{c}\text { Initial } \\
\text { density }(\%)\end{array}$ & $\begin{array}{c}\text { Flyer } \\
\text { velocity } \\
(\mathrm{km} / \mathrm{s})\end{array}$ & \multicolumn{1}{c}{ Recovered results } \\
\hline 998 & 60 & 1.95 & Recovery capsule disintegrated \\
1000 & 61 & 1.75 & Same \\
1004 & 60 & 1.95 & Small aliquot recovered \\
\hline \hline
\end{tabular}

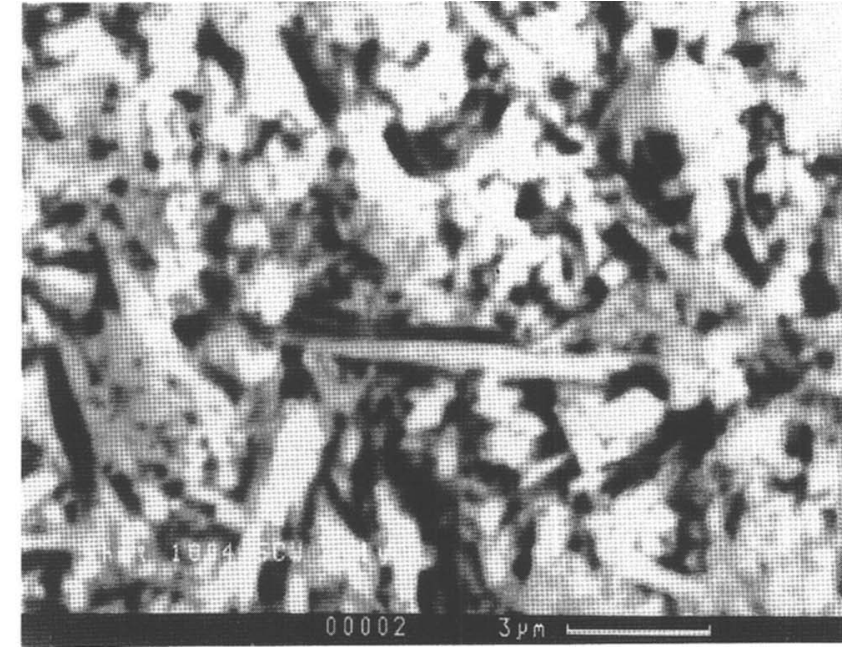

FIG. 6. Many SCW retain their original form after a $13 \mathrm{GPa}$ shock compression (shot 1004).

tween phases, and in which phase shock induced cracks occurred.

Diamond samples consolidated with both SiC powder and SCW were sliced (to $0.5 \mathrm{~mm}$ thick) and then polished via a two-step abrasion with diamond paste to reduce their thickness down to 70-200 $\mu \mathrm{m}$. After polishing, the samples were ion milled for $\sim 100 \mathrm{~h}$ down to electron transparency $(\sim 10-100 \mathrm{~nm})$ thick in a Commonwealth Scientific STATMMI-2 argon-ion milling apparatus. The temperature rise from room temperature was $\sim 200{ }^{\circ} \mathrm{C}$ during ion thinning. These foils were in turn examined in a $100 \mathrm{keV}$ JEOL Model $100 \mathrm{C}$ TEM. The question of possible dislocation motion in the course of ion-milling for $100 \mathrm{~h}$ at $\sim 500 \mathrm{~K}$ was examined. Assuming a vacancy formation and migration model in which the self-diffusion activation energy is estimated to be $\sim 7 \mathrm{eV}$, the diffusional losses of dislocations are calculated to be negligible for post-shock heating of $3000 \mathrm{~K}$ for $10 \mathrm{~ms}$ or during ion milling.

Both bright-field [Fig. 8(a)] and dark-field images [Figs. $8(\mathrm{c})$ and $8(\mathrm{~d})$ ] of the diamond admixed with the initially $0.28 \mu \mathrm{m} \beta-\mathrm{SiC}$ powder from shot 983 (see Table III) demonstrate that the $\mathrm{SiC}$ has completely recrystallized. Although a few grains appear to be as large as $\sim 100 \mathrm{~nm}(0.1 \mu \mathrm{m})$ virtually all the single crystal domains are now in the size range of $30 \mathrm{~nm}$ or smaller, and the crystal orientation of the recrystallized $\mathrm{SiC}$ appears to be truly random. Moreover, the boundaries between what we assume to be recrystallized $\beta-\mathrm{SiC}$ and the diamond are smooth and in several cases are straight, indicating that interpenetrative motion between the diamond and $\mathrm{SiC}$ phase has been minimal. We infer that the diamond phase has not melted and recrystallized. There are no indications of reaction or solid solution between the diamond and SiC phases. 
TABLE VIII. Shock consolidation of diamond plus Si powder.

\begin{tabular}{|c|c|c|c|c|c|}
\hline \multirow[b]{2}{*}{ Shot no. } & \multicolumn{2}{|c|}{ Mass fraction $(\%)$} & \multirow{2}{*}{$\begin{array}{c}\text { Initial } \\
\text { density }(\%)\end{array}$} & \multirow{2}{*}{$\begin{array}{l}\text { Flyer velocity } \\
\qquad(\mathrm{km} / \mathrm{s})\end{array}$} & \multirow[b]{2}{*}{ Recovered results } \\
\hline & Diamond & $\mathrm{Si}$ & & & \\
\hline $807^{\mathrm{a}}$ & 95 & 5 & 60 & 1.18 & Hard, scratches glass \\
\hline 1024 & 95 & 5 & 60 & 1.94 & Harder than 807 , scratches $\mathrm{Al}_{2} \mathrm{O}_{3}$ \\
\hline 1026 & 90 & 10 & 60 & 2.01 & Same \\
\hline 1027 & 95 & 5 & 60 & 1.90 & Same \\
\hline 1031 & 95 & 5 & 60 & 2.0 & Same \\
\hline
\end{tabular}

$\overline{{ }^{a} \text { Sandwiched with } \mathrm{Ti}+\mathrm{C} \text {. }}$

The texture of the consolidated diamond plus SCW (Figs. 9 and 10) can be seen to be somewhat different. In Fig. 10 we again see the diamond surrounded by recrystallized $\mathrm{SiC}$. However, the boundaries between the diamond crystal and the $\mathrm{SiC}$ are less smooth than in Fig. 8, for which the $\mathrm{SiC}$ started out as powder rather than whisker. The diamond is not heavily deformed in the sample from this experiment and, upon tilting the TEM stage, demonstrates a clear and consistent lack of the presence of dislocations. Thus we infer that the diamond phase undergoes only elastic deformation and brittle failure. The thermal history of the material (see below) makes it unlikely that the absence of dislocations is due to annealing. The crystal habit of the SiC material which started out as whisker can be seen to be completely different in the dark-field images [Figs. 9(c) and 9(d)] versus the sample where it started out as powder [Figs. 8(c) and 8(d)]. The SCW material has recrystallized into a series of quasilinear and coherent crystal bundles. Their dimensions are on the order of $\sim 50$ by $150 \mathrm{~nm}$. Moreover, some open

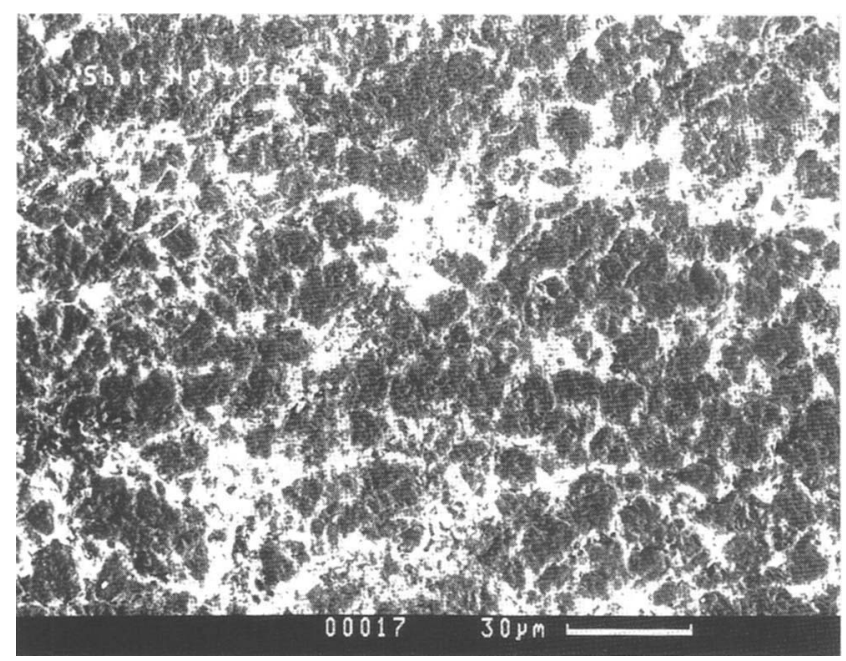

FIG. 7. SEM image of diamond plus Si powder in shot 1026. Completely melted Si gives the diamond grains a good bonding and all the diamond grains are fractured under shock loading. cracks $\sim 200 \mathrm{~nm}$ long and 10-20 nm wide can be observed to terminate these bundles in Fig. 9(a). We think these microcracks are due to the volume contraction during consolidation. The deformation features in the diamond itself are well demonstrated in Fig. 11. Just like the SEM observations, the TEM images reveal that extensive brittle (presumably crystallographically controlled) cracking is present within individual diamond grains. Moreover, the crystal boundaries are not seriously deformed. The dark-field image [Fig. 11(b)] and the corresponding diffraction pattern [Fig. 11(c)] indicate that a moderate degree of streaking of the diffraction spots and microcrystalline rotation have occurred, and $100-300 \mathrm{~nm}$ regions of the crystal have been rotated via brittle shear strains. This microcrystalline rotation is not attributed to plastic deformation followed by annealing to give dislocation-free subgrains, because of the thermal history of the sample. The sample was shocked up to about $1000 \mathrm{~K}$ (see Table IV) by a shock wave with duration of about $1.5 \mu \mathrm{s}$. After the shock, it was heated up to about $3000 \mathrm{~K}$ by post-shock heating within a few milliseconds (see Sec. VI) and then cooled down to ambient temperature in approximately the same time interval. Thus, as discussed above, there was not enough time at high enough temperature for the dislocations to distribute themselves entirely into subboundaries.

We conclude from the TEM images that very little of the consolidation observed in the diamond-SiC system resulted from diamond grain boundary melting. The consolidated samples contain diamond held together with extensively melted and recrystallized $\beta-\mathrm{SiC}$; there is no evidence to suggest plastic deformation of the diamond. The bundle fiber texture of the soundly consolidated material obtained with the recrystallized $\mathrm{SCW}$ versus the equant texture resulting from the melted recrystallized $\mathrm{SiC}$ powder gives rise to a marked difference in the resulting sample. The formation of equant microcrystallites implies that many crystal seeds were formed at the same time in the melted $\mathrm{SiC}$ and the $\mathrm{SiC}$ powder material achieved a lower temperature compared with the SCW which formed bundle-like crystallites. ${ }^{12}$ The TEM and SEM analyses indicate that we need a thermo- 

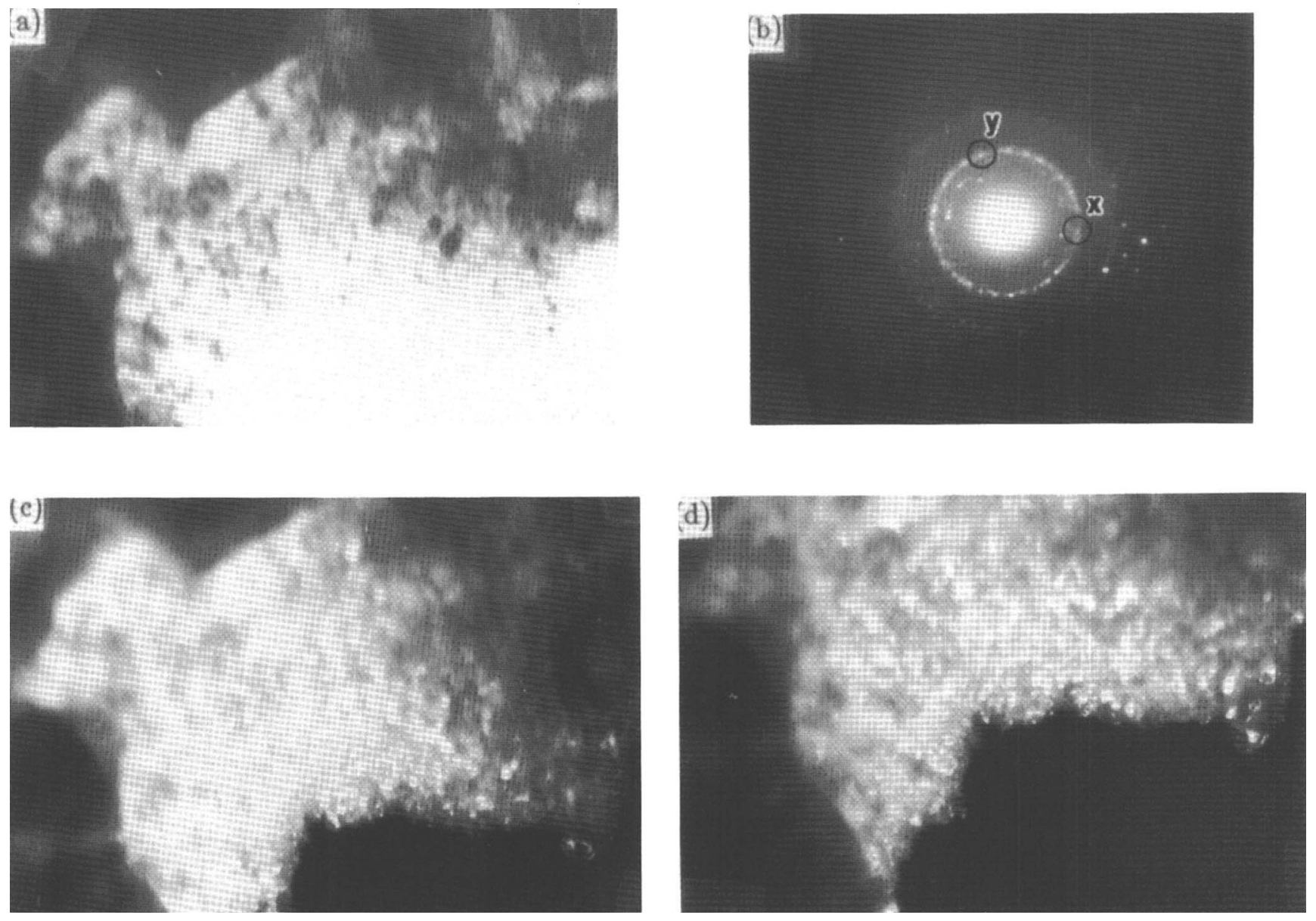

$300 \mathrm{~nm}$

FIG. 8. TEM image of shot 983. Bright-field image (a) and diffraction pattern (b) of region of submicron SiC crystals; dark-field images, (c) and (d), taken for regions $x$ and $y$ of the diffraction pattern.

dynamic model that predicts, especially for the whiskers, virtually complete shock-induced melting of the $\mathrm{SiC}$ and no plastic deformation or significant melting of the diamond.

\section{A NEW CALCULATION MODEL}

Previously, in describing the thermodynamics of shock consolidation of superhard materials admixed with whiskers, ${ }^{7}$ we employed a rather standard continuum approach. We assumed the hard power material and the whisker material could be described as having the same initial porosity. We also assumed that, upon shock loading, each phase was driven to an equal shock pressure along its individual porous Hugoniot. Our present observations, however, indicate that more melting occurs in the whisker material than is calculated from this previous model. Allowance must be made for the somewhat lower (ambient) melting points of $\mathrm{SiC}(2963 \mathrm{~K})$ and
$\mathrm{Si}_{3} \mathrm{~N}_{4}(2173 \mathrm{~K})$ as compared to diamond $(4300 \mathrm{~K})$ and c-BN $(3273 \mathrm{~K})$ as well as for the greater compressibility of $\mathrm{SiC}$ or $\mathrm{Si}_{3} \mathrm{~N}_{4}$ (see Ref. 7, Figs. 3 and 5). As described in the previous sections, however, the contrast in melting behavior, especially for the admixtures with whiskers, appears to be considerably greater than would be expected on this basis alone. We think that in the vicinity of whiskers in the mixture, a larger effective porosity exists than in the coexisting powders. Thus the whisker material will have more space in which to achieve a locally higher compressional energy deposit, which is inferred to result in excess melting of the whiskers during shock consolidation, than the powder material.

In order to get the excess porosity of the essentially rod-like whiskers admixtured with approximately cubeshaped crystals, some packing information is needed. Milewski ${ }^{13,31}$ did systematic packing experiments of sphere-rod mixtures. It turns out that the distension, $M$, 

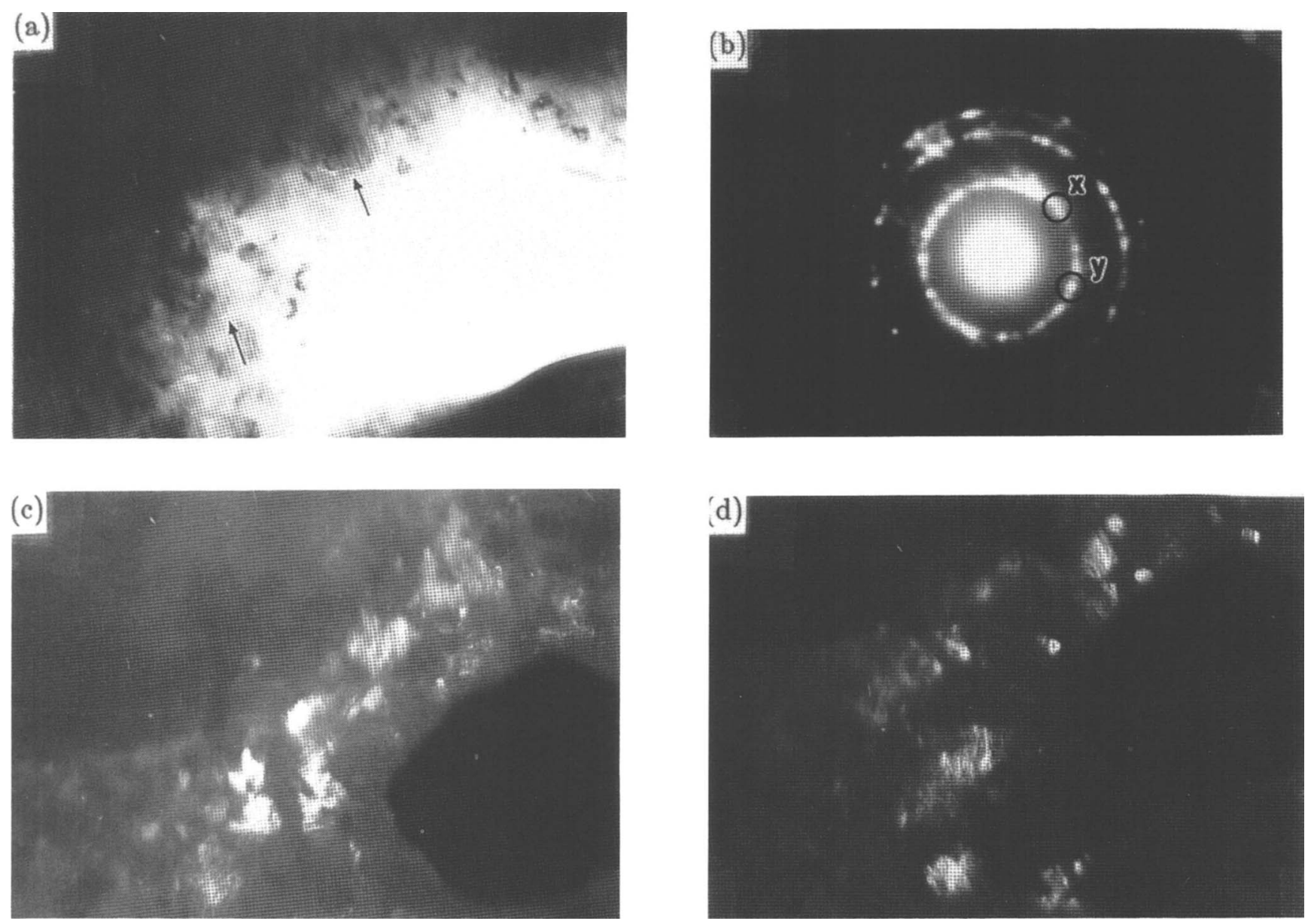

\section{$200 \mathrm{~nm}$}

FIG. 9. TEM image of shot 973. Bright-field image (a) and diffraction pattern (b) of region of submicron SiC crystals observed between diamond single crystals; dark-field images, (c) and (d), taken for regions $x$ and $y$ of the diffraction pattern. Arrows in (a) indicate small cracks.

of the mixture is a function of the length to diameter ratio, $L / D_{r}$, of the rods, the diameter ratio, $D_{s} / D_{r}$, of spheres to rods, and the solid volume fraction (without porosity), $F$, of the rods. $M$ is defined as the ratio of the volume with porosity divided by the pore-free volume. In our consolidation experiments, the average $L / D_{s}$ is about 50, average $D_{s} / D_{r}$ is about 3 to 4 , and $F$ ranges from about 0.1 to 0.4 . Packing data with $D_{s} / D_{r}=1.95,3.71$, $6.97,14.32$, and 17.4 are obtained by Milewski. The data with $D_{s} / D_{r}=3.71$ are used. Figure 12 shows the data with $D_{s} / D_{r}=3.71$ and some experimental points we conducted for $D_{s} / D_{r}=3$. The vertical axis is distension of the mixture, and the axis of abscissa is the length to diameter ratio of whiskers. Unfortunately, there are no data for $L / D_{r}$ equal to 50 , which we need. Hence, we simply fit the data and extrapolate them to $L / D_{r}=50$. In fitting the data, we made an assumption that if $F$ and $D_{s} / D_{r}$ are constant, when $L$ becomes very large, $M$ equals the distension with no rods, $M_{0}=1.624$. This assumption is reasonable in considering the geometry of the mixture. That is, when the rods become longer, the number density of the rods will decrease and the excess porosity generated will decrease and thus the distension will decrease.

The distension $M$ at $L / D_{r}=50$ for different $F$ were fitted as

$$
M=1.552+0.03279 \exp (7.633 F)
$$

$$
(0.1<F<0.4)
$$

So, we have

$$
\begin{array}{r}
\left(M-M_{0}\right) / M_{0}=-0.04433+0.0202 \exp (7.633 F) \\
(0.1<F<0.4)
\end{array}
$$

where $M-M_{0}$ is the distension increase because of the addition of rods, $\Delta M$.

Assuming that in our sample, the distension increase and the distension of pure crystal have the same relation 

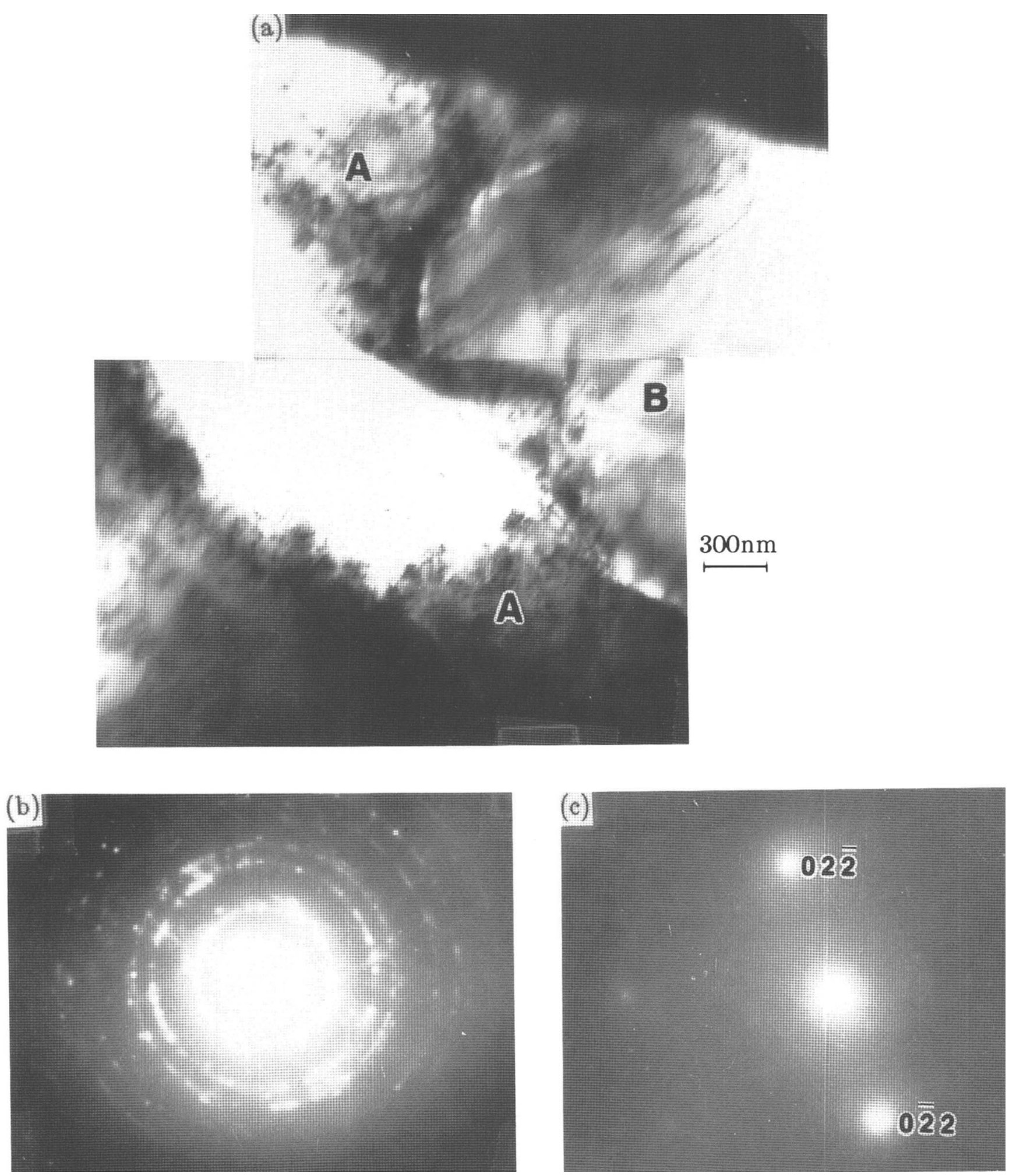

FIG. 10. TEM image of shot 973. (a) Montage showing regions of small SiC crystals (A) surrounding diamond single crystal (B); (b) and (c) diffraction patterns from regions (A) (lower) and (B), respectively.

as shown in Eq. (2), plus the distension conservation condition of the mixture

$$
M=M_{0}+\Delta M
$$

we can calculate the distension of crystals, $M_{0}$, and the distension increase because of the addition of whiskers, $\Delta M$. Designating $\Delta M$ to whiskers only, we get the bulk densities of crystals and whiskers, respectively. For 

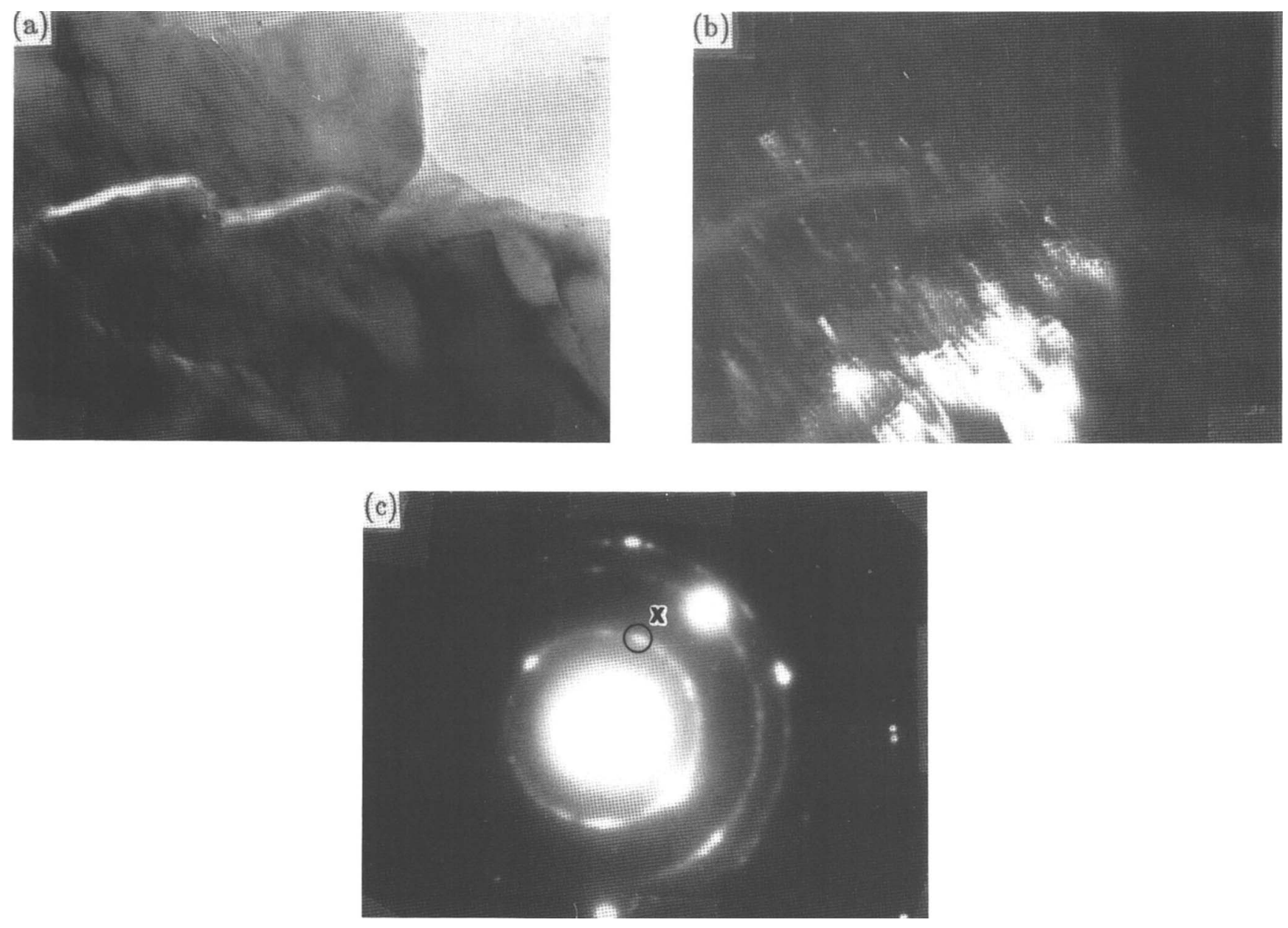

$100 \mathrm{~nm}$

FIG. 11. TEM image of shot 767. Bright-field (a) and dark-field (b) images and diffraction pattern (c) of diamond region showing small crystals and cracking. Dark-field image taken for region $x$ in diffraction pattern.

example, in shot 953 (Table I), with $M=1.538$ and $F=0.174$, we get $M_{0}=1.491$ and $\Delta M=0.047$; the bulk densities of diamond and SNW are $67.1 \%$ and $56.8 \%$ of their crystal densities, respectively.

After the initial densities of powders and whiskers in the admixture were obtained by the procedure outlined above, a series of thermodynamic calculations were conducted. Shock pressure, $P_{H}$, temperature, $T_{H}$, postshock temperature, $T_{p}$, and percent of material melted, $L$, were calculated. The results are presented in Tables I-II, IV-V, and IX-X. The assumptions in the calculation are the same as before ${ }^{7}$ except that the powders and whiskers have different initial densities. Details of the calculations are presented in the appendix. The parameters used are listed in Table XI. Table IX and Table $X$ give the results of the revised calculations for the experiments described in Ref. 7. The new calculation predicts much higher shock temperatures and more melting of the whisker materials SNW and SCW. For example, for shot 936 (Table IX), the new calculation yields $73.3 \%$ melt and a shock temperature of $2173 \mathrm{~K}$ (melting point) of SNW, whereas the previous one yields only $48.8 \%$ melt and $1876 \mathrm{~K}$. We believe that, at such high temperatures (near or at the melting point), the whisker material will lose its strength completely and change shape, either plastically or by fluid flow, to form the observed texture in the recovered sample. In contrast, the diamond and c-BN powders achieve relatively low temperatures compared with their melting points and are therefore neither plastically deformed nor extensively melted.

\section{POST-SHOCK HEATING WITH Ti $+\mathbf{C}$}

The concept of post-shock heating was first suggested by Sawaoka and Akashi. ${ }^{8}$ The reason we use titanium plus carbon as a heat source is that the reaction 


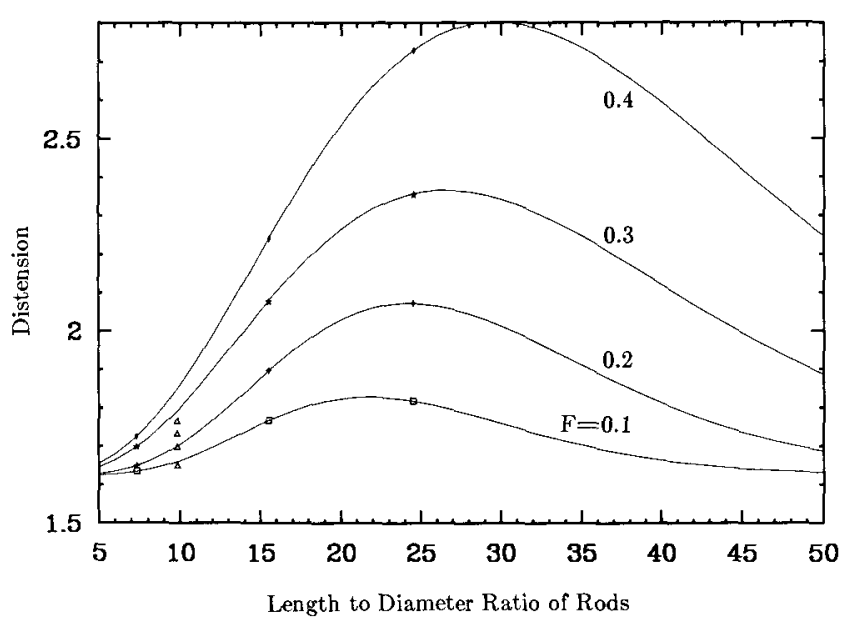

FIG. 12. Distension of sphere rod mixture versus length to diameter ratio of rods. The data points are Milewski's data ${ }^{31}$ for $D_{s} / D_{r}=3.71$. The solid lines are fitted lines at different solid volume fraction, $F$, of rods. The triangle symbols are our packing results with $D_{s} / D_{r}=3$.

has a large reaction heat ${ }^{17}(\Delta H=3037 \mathrm{~J} / \mathrm{g})$ and the titanium and carbon can react completely with each other under shock compression. ${ }^{8} \mathrm{Fe}_{2} \mathrm{O}_{3}$ plus $\mathrm{Al}$ may also be a good candidate for post-shock heating (its reaction heat is about $4000 \mathrm{~J} / \mathrm{g}$ when completely reacted), but Boslough has studied this reaction under shock-wave loading and pointed out that reaction under shock may be incomplete. 22

The Ti powder we used has a size range of $1-3 \mu \mathrm{m}$ and is mixed with carbon black in a stoichiometric ratio. The reaction equation is

$$
\mathrm{Ti}+\mathrm{C}=\mathrm{TiC}
$$

If $T$ is the post-shock temperature of the product $\mathrm{TiC}$, the energy balance equation is

$$
\Delta H+E_{H}=\int_{300}^{T} C_{p} d T+L \Delta H_{m}
$$

where $E_{H}$ is the Hugoniot energy, $C_{p}$ is the specific heat of $\mathrm{TiC}^{17} \mathrm{~L}$ is the melting fraction of $\mathrm{TiC}$, and the latent heat $\Delta H_{m}$ of melting of TiC is $1187 \mathrm{~J} / \mathrm{g} .{ }^{17}$ The Hugoniot energy is dependent on the shock pressure and the initial state of $\mathrm{Ti}+\mathrm{C}$. If the crystal specific volume $V_{0 c}$ of $\mathrm{TiC}$ is used as an approximation of the Hugoniot specific volume, then $E_{H}$ is given approximately as

$$
E_{H}=\frac{1}{2} P_{H}\left(V_{00}-V_{0 c}\right)
$$

where $V_{00}$ is the initial specific volume of $\mathrm{Ti}+\mathrm{C}$, and $V_{0 c}$ equals $0.2025 \mathrm{~cm}^{3} / \mathrm{g}{ }^{17}$ The appendix describes how the $\mathrm{Ti}+\mathrm{C}$ Hugoniot is derived.

If $\phi$ is the initial fractional porosity, $E_{H}$ can be expressed as

$$
E_{H}=\frac{1}{2} P_{H} V_{0 c} \frac{\phi}{1-\phi}
$$

With Eqs. (4) and (6), we get the $T-P_{H}$ relation at different values of $\phi$. For example, for $\phi=40 \%$, the reaction heat itself will heat the $\mathrm{TiC}$ to its melting point (3293 K) and melt $48.5 \%$ of it when $P_{H}=0$; when $P_{H}=9.05 \mathrm{GPa}$, the $\mathrm{TiC}$ will be completely melted. Some calculational results are illustrated in Fig. 13. It is clear that the higher the pressure or the greater the initial porosity, the higher the post-shock temperature

\begin{tabular}{|c|c|c|c|c|c|c|c|c|c|}
\hline \multicolumn{10}{|c|}{ Experiments } \\
\hline \multirow[b]{2}{*}{ Shot no. } & & \multicolumn{3}{|c|}{ Mass fraction $(\%)$} & \multirow{2}{*}{$\begin{array}{c}\text { Initial } \\
\text { density (\%) }\end{array}$} & \multirow{2}{*}{\multicolumn{2}{|c|}{$\begin{array}{c}\text { Flyer velocity } \\
(\mathrm{km} / \mathrm{s})\end{array}$}} & \multirow{2}{*}{\multicolumn{2}{|c|}{ Recovered results }} \\
\hline & & $c-B N$ & \multicolumn{2}{|c|}{ SNW } & & & & & \\
\hline 932 & & 85 & & & 60 & & 95 & Consol & \\
\hline 936 & & 85 & & & 71 & & 94 & Well c & ted \\
\hline \multicolumn{10}{|c|}{ Calculations } \\
\hline & \multicolumn{2}{|c|}{ Initial density $(\%)$} & & \multicolumn{2}{|c|}{$T_{H}(\mathrm{~K})$} & \multicolumn{2}{|c|}{$T_{p}(\mathrm{~K})$} & \multicolumn{2}{|c|}{$L(\%)$} \\
\hline Shot no. & $\mathrm{c}-\mathrm{BN}$ & SNW & $P_{H}(\mathrm{GPa})$ & $\mathrm{c}-\mathrm{BN}$ & SNW & $c-B N$ & SNW & $c-B N$ & SNW \\
\hline \multirow[t]{2}{*}{932} & 61.5 & 53.2 & 20.0 & 1530 & 2173 & 1508 & 2173 & 12.5 & 85.4 \\
\hline & & & & $1154^{\mathrm{a}}$ & $2081^{a}$ & & & $11.3^{\mathrm{a}}$ & $55.4^{\mathrm{a}}$ \\
\hline \multirow[t]{2}{*}{936} & 72.8 & 63 & 25.7 & 1314 & 2173 & 1279 & 2173 & 9.5 & 73.3 \\
\hline & & & & $929^{\mathrm{a}}$ & $1876^{\mathrm{a}}$ & & & $8.8^{\mathrm{a}}$ & $48.8^{\mathrm{a}}$ \\
\hline
\end{tabular}
that the TiC will reach; that is, more heat will be released from $\mathrm{TiC}$.

TABLE IX. Revised calculation results for c-BN plus SNW shock consolidation experiments.

${ }^{\mathrm{a} \text { Results from Ref. } 7 .}$ 
TABLE X. Revised calculation results for c-BN plus SCW shock consolidation experiments.

\begin{tabular}{|c|c|c|c|c|c|c|c|c|c|}
\hline \multicolumn{10}{|c|}{ Experiments } \\
\hline \multirow[b]{2}{*}{ Shot no. } & & \multicolumn{2}{|c|}{ Mass fraction $(\%)$} & \multirow{2}{*}{\multicolumn{2}{|c|}{$\begin{array}{c}\text { Initial } \\
\text { density }(\%)\end{array}$}} & \multirow{2}{*}{\multicolumn{2}{|c|}{$\begin{array}{l}\text { Flyer velocity } \\
(\mathrm{km} / \mathrm{s})\end{array}$}} & & \\
\hline & & $\mathrm{c}-\mathrm{BN}$ & SCW & & & & & \multicolumn{2}{|c|}{ Recovered results } \\
\hline 937 & & 85 & 15 & & & & & Uncom & \\
\hline 938 & & 80 & 20 & & & & & Consol & \\
\hline 939 & & 75 & 25 & & & & & Consol & riable \\
\hline \multicolumn{10}{|c|}{ Calculations } \\
\hline & \multicolumn{2}{|c|}{ Initial density $(\%)$} & & \multicolumn{2}{|c|}{$T_{H}(\mathrm{~K})$} & \multicolumn{2}{|c|}{$T_{p}(\mathrm{~K})$} & \multicolumn{2}{|c|}{$L(\%)$} \\
\hline Shot no. & $\mathrm{c}-\mathrm{BN}$ & SCW & $P_{H}(\mathrm{GPa})$ & $c-B N$ & SCW & c-BN & SCW & $\mathrm{c}-\mathrm{BN}$ & SCW \\
\hline \multirow[t]{2}{*}{937} & 72.8 & 63.0 & 27.2 & 1362 & 2587 & 1324 & 2479 & 10.1 & 31.4 \\
\hline & & & & $968^{\mathrm{a}}$ & $1972^{\mathrm{a}}$ & & & $9.3^{\mathrm{a}}$ & $19.7^{\mathrm{a}}$ \\
\hline \multirow[t]{2}{*}{938} & 74.2 & 58.0 & 25.2 & 1245 & 2868 & 1213 & 2769 & 9.6 & 35.8 \\
\hline & & & & $937^{\mathrm{a}}$ & $1834^{\mathrm{a}}$ & & & $9.0^{\mathrm{a}}$ & $19.2^{\mathrm{a}}$ \\
\hline \multirow[t]{2}{*}{939} & 78.9 & 55.7 & 26.1 & 1101 & 2963 & 1067 & 2963 & 6.9 & 40.8 \\
\hline & & & & $895^{\mathrm{a}}$ & $1845^{\mathrm{a}}$ & & & $8.8^{\mathrm{a}}$ & $18.9^{\mathrm{a}}$ \\
\hline
\end{tabular}

a Results from Ref. 7.

In the shock consolidation, the post-shock heating is probably very important, especially in the comparatively low pressure range. Successful shock compaction is probably impossible under low pressure without postshock heating, for the following reasons. Under low pressure, very little melt can be obtained and this will not be sufficient to bond the particles together. The relatively low shock pressure also implies that the brittle particles will not be able to change their shape plastically to give a dense compact. In addition, the rapid cooling of the sample will induce cracks. In the case of post-shock heating via the $\mathrm{Ti}+\mathrm{C}=\mathrm{TiC}$ reaction, the sample is able to cool slowly and thus eliminate the formation of cracks due to rapid cooling, and remove residual stresses. The post-shock heating can also heal the cracks induced during the pressure release process and possibly also remove voids from the sample via conventional sintering action. Shot 808 (see Table V) was conducted without $\mathrm{Ti}+\mathrm{C}$. The flyer velocity is $1.36 \mathrm{~km} / \mathrm{s}$ (almost the same as shot 786). The recovered sample is uncompacted. These two shots exemplify the importance of post-shock heating of the sample by TiC formation.

As an example, we calculated the time dependent temperature profiles of shot 766 (Table IV, Fig. 15) for the geometry shown in Fig. 14. We assumed that, after shock loading, the sample, TiC, and 304 stainless steel (S.S.304) capsule are each at their crystal density, and that the heat flow is one-dimensional. We chose a typical initial sample thickness of $2 \mathrm{~mm}$, but varied the thickness of $\mathrm{TiC}$ from 0.25 to $1.0 \mathrm{~mm}$ corresponding to the thickness of $\mathrm{Ti}+\mathrm{C}$ from 0.8 to $1.7 \mathrm{~mm}$ at porosity of $40 \%$.

TABLE XI. Parameters.

\begin{tabular}{|c|c|c|c|c|}
\hline & Diamond & $\mathrm{c}-\mathrm{BN}$ & SCW & SNW \\
\hline$\gamma_{0}$ & $0.9^{14}$ & $1.87^{18}$ & $1.25^{20}$ & $1.25^{\mathrm{a}}$ \\
\hline$C_{0}(\mathrm{~mm} / \mu \mathrm{s})$ & $12.16^{14}$ & $10.29^{18}$ & $8.0^{20}$ & $7.90^{21}$ \\
\hline$S$ & $1.00^{14}$ & $1.25^{18}$ & $0.95^{20}$ & $1.20^{21}$ \\
\hline$\rho_{0}\left(\mathrm{~g} / \mathrm{cm}^{3}\right)$ & $3.51^{15}$ & $3.487^{15}$ & $3.18^{15}$ & $3.18^{15}$ \\
\hline$\theta(\mathrm{K})$ & $1600^{16}$ & $1900^{16}$ & $1140^{20}$ & $1067^{\mathrm{b}}$ \\
\hline$T_{m}(\mathrm{~K})$ & $4300^{17}$ & $3273^{7}$ & $2963^{15}$ & $2173^{1}$ \\
\hline$H_{m}(\mathrm{~kJ} / \mathrm{g})$ & $9.2^{19}$ & $9.2^{19}$ & $4.9^{19}$ & $1.081^{\mathrm{C}}$ \\
\hline
\end{tabular}

$\gamma_{0}$ : Grüneisen coefficient; $C_{0}$ and $S:$ constants in $D=C_{0}+S U ; \rho_{0}$ : crystal density; $\theta$ : Debye temperature; $T_{m}:$ melting point; $H_{m}:$ latent heat of melting.

${ }^{\mathrm{a}} \mathrm{SiC}$ value.

${ }^{b}$ Derived from its specific heat at $298 \mathrm{~K}$ in Ref. 15.

${ }^{c}$ Estimated by assuming that it has the same entropy increase per mole upon melting as that of SiC. 


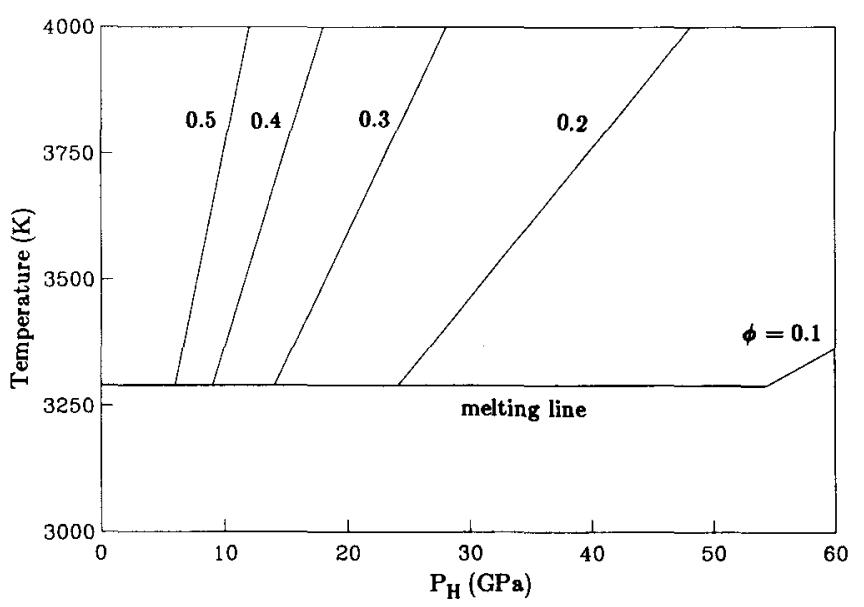

FIG. 13. Post-shock temperature of TiC versus shock pressure $P_{H}$ at different initial porosity $(\phi)$. Melting line shown is appropriate for $\mathrm{TiC}$.

To solve the one-dimensional heat equation, a finite differential numerical method was employed. ${ }^{23}$ The thermal diffusivities used here are $4 \times 10^{-6} \mathrm{~m}^{2} / \mathrm{s}$ (S.S.304), ${ }^{24} 10^{-4} \mathrm{~m}^{2} / \mathrm{s}$ (diamond), ${ }^{7}$ and $5 \times 10^{-6} \mathrm{~m}^{2} / \mathrm{s}$ (SCW). ${ }^{7}$ For simplicity, a constant specific heat of $0.4 \mathrm{~J} / \mathrm{gK}^{24}$ was assumed for S.S.304. The Debye specific heat model was used for diamond (Debye temperature, $1860 \mathrm{~K}$ ) (see Table XI) and SCW (Debye temperature, $1140 \mathrm{~K}$ ) (see Table XI). To simplify the calculation further, we chose the thermal diffusivity of $\mathrm{TiC}$ as infinite. The post-shock temperature rise of S.S.304 was omitted, for it is small. ${ }^{20}$ The calculation results are shown in Fig. 15. Calculations were performed for four different thicknesses of TiC. We can see from Fig. 15 that a thicker TiC layer gives the sample a higher average temperature. In Fig. 15(d), an average temperature of $3000 \mathrm{~K}$ [higher than the melting point $(2963 \mathrm{~K})$ of SCW] was obtained and the SCW in the sample must be melted

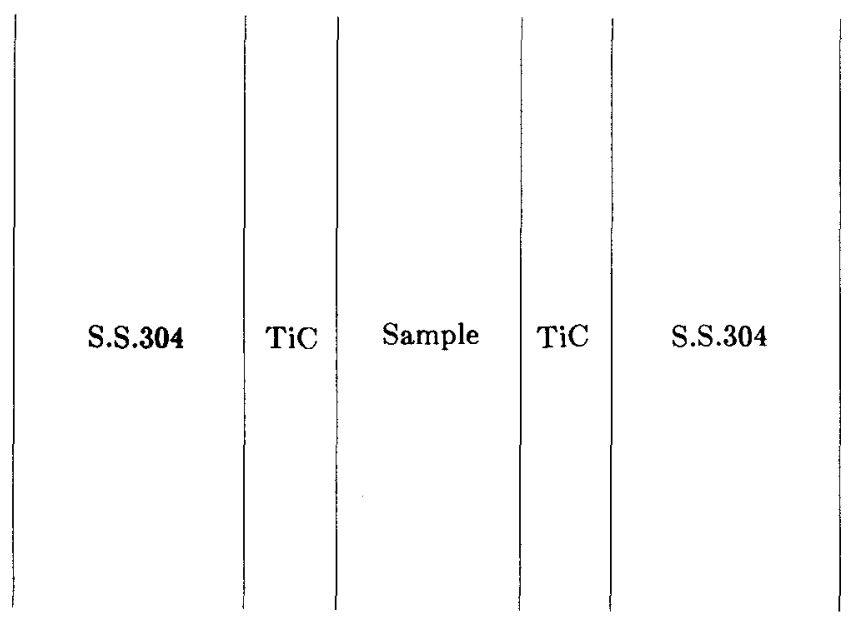

FIG. 14. Geometry assumed in calculation of post-shock heating. in this case. In Fig. 15(b), with a TiC thickness of $0.5 \mathrm{~mm}$, which corresponds to $0.83 \mathrm{~mm}$ porous $\mathrm{Ti}+\mathrm{C}$, the average temperature of the sample reached $2370 \mathrm{~K}$, which is $80 \%$ of the melting point of SCW. It is known that the carbides will lose their brittleness at a temperature $80-90 \%$ of their melting points. ${ }^{25}$ So we infer that SCW will be efficiently annealed in this case. The optimum thickness for this proposed process is approximately 0.8 to $1.7 \mathrm{~mm}$ when the initial porosity of $\mathrm{Ti}+\mathrm{C}$ is $40 \%$, under a shock pressure of $10 \mathrm{GPa}$ which is typical of these experiments. The porous $\mathrm{Ti}+\mathrm{C}$ thicknesses we used in the present experiments were $0.8-1.5 \mathrm{~mm}$, which are very close to what we infer is optimum from the calculations.

\section{DISCUSSION AND CONCLUSION}

The shock wave consolidation mechanism in an admixture of a superhard powder and a whisker material is the melting and recrystallizing of the whisker material. Rod-like whiskers have a higher effective porosity as compared with the average environment of cube-shaped crystals in the mixture. Whisker deformation and melting are enhanced by this excess space. We note that the whisker materials have lower melting temperature and strength as compared with diamond or c-BN powder. In contrast, when fine SiC powder is admixed with spherelike diamond or $\mathrm{c}-\mathrm{BN}$ powder, it fills the voids between the particles and no excess space can be obtained. Thus the fine SiC powder results in lower post-shock temperatures upon shock consolidation and therefore is not suitable as an additive material. Our new calculation model of powder plus whisker provides a physically based explanation of the experimental results.

The effect of post-shock heating obtained from the reaction $\mathrm{Ti}+\mathrm{C}=\mathrm{TiC}$ is important in consolidation under low dynamic pressure. Very well consolidated samples composed of c-BN plus SCW were obtained with the post-shock heating technique for shock compaction at a pressure of $12 \mathrm{GPa}$.

Brittle failure of synthetic diamond crystals during shock loading occurred in most of our experiments. In comparison, c-BN single crystals appear to be unaffected by shock loading when admixed with whisker material.

The SNW material, because of its reaction with carbon under higher temperature and pressure, is not suitable for shock compaction when mixed with diamond powder; the SCW yields better compacts.

The commercially obtained Si powder $(<44 \mu \mathrm{m})$ shows some promise as a beneficial additive in consolidation of diamond. Well-consolidated diamond samples were obtained with $5 \%$ or $10 \%$ Si. Further work needs to be conducted in this area.

It appears, at present, that c-BN plus SCW is the most promising material to obtain practically 


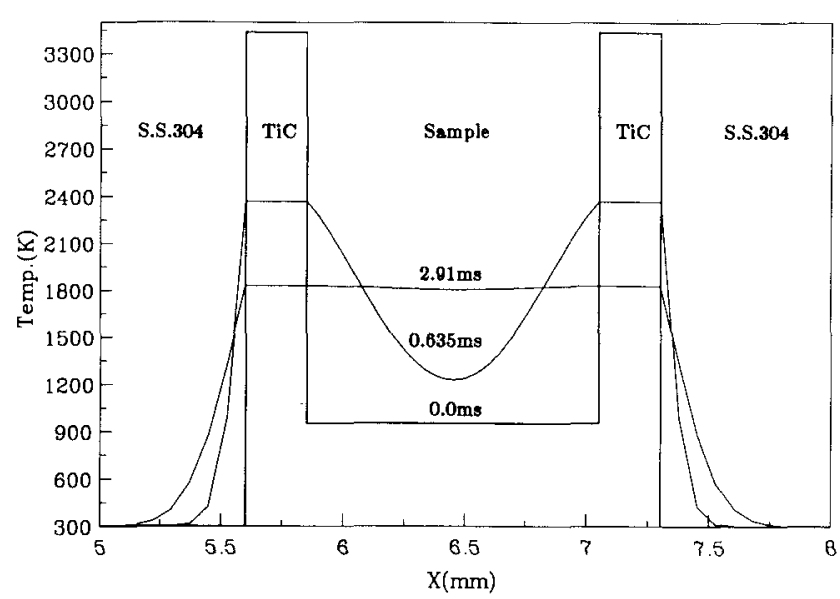

(a)

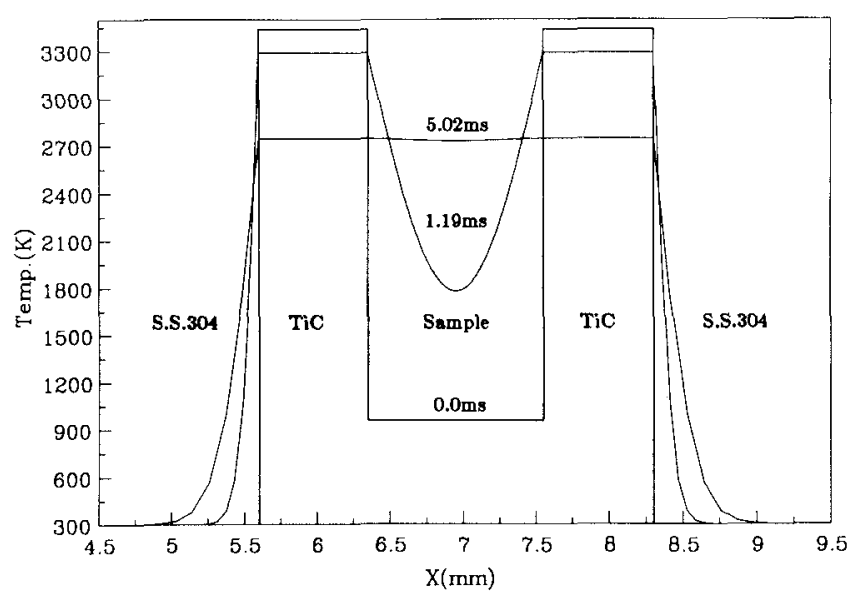

(c)

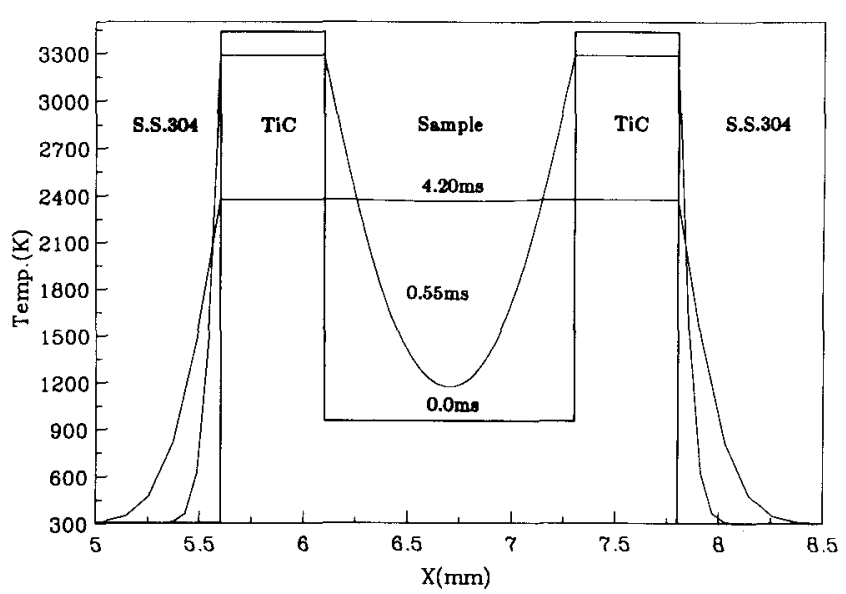

(b)

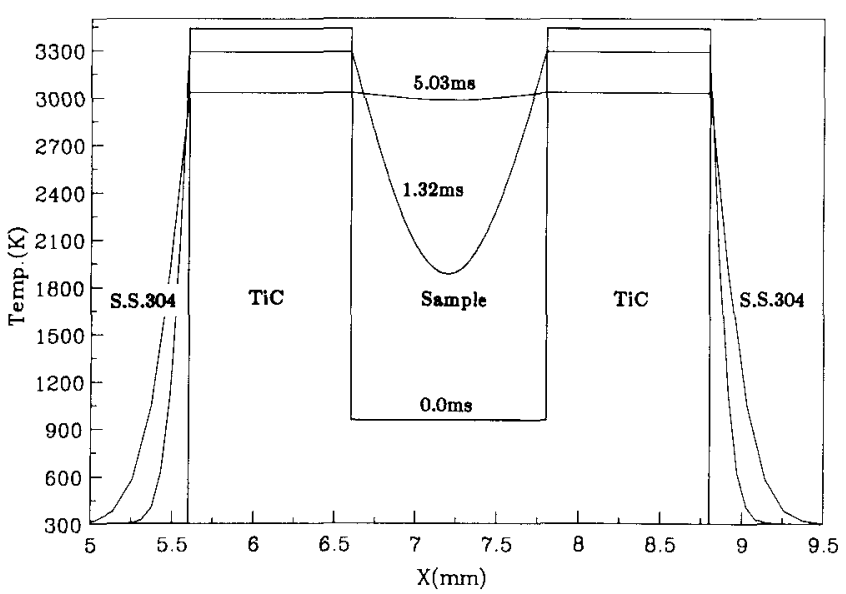

(d)

FIG. 15. Calculated temperature profiles of post-shock heating. (a) The thickness of TiC is $0.25 \mathrm{~mm}$, and the average temperature of the sample reaches $1819 \mathrm{~K}$ at $2.91 \mathrm{~ms}$; (b) TiC $0.5 \mathrm{~mm}$ thick, average temperature $2370 \mathrm{~K}$ at $4.20 \mathrm{~ms}$; (c) TiC 0.75 thick, average temperature $2737 \mathrm{~K}$ at $5.02 \mathrm{~ms}$; (d) TiC $1.0 \mathrm{~mm}$ thick, average temperature $3000 \mathrm{~K}$ at $5.03 \mathrm{~ms}$.

useful superhard polycrystalline compacts via shock consolidation.

\section{ACKNOWLEDGMENTS}

This research was supported by California Institute of Technology, New Mexico Institute of Mining and Technology, and United States Army Research Office Contract No. DAAL03-88-K-0199, contribution number 4869, Division of Geological and Planetary Sciences.

\section{REFERENCES}

1. D. K. Potter and T.J. Ahrens, Appl. Phys. Lett. 51, 317-319 (1987).

2. F. P. Bundy and R. H. Wentorf, J. Chem. Phys. 38, 1144-1149 (1963).

3. T. Akashi, V. Lotrich, A. Sawaoka, and E. K. Beauchamp, J. Am. Ceram. Soc. 68, c-322-c-324 (1985).

4. T.J. Ahrens and D.K. Potter, in Shock Waves in Condensed Matter-1987, edited by S.C. Schmidt and N. C. Holmes (NorthHolland Physics Publishing, Amsterdam, The Netherlands, 1988), pp. 419-422.
5. S. Sawai and K. Kondo, J. Am. Ceram. Soc. 71, c-185-c-188 (1988).

6. T. Akashi and A.B. Sawaoka, J. Mater. Sci. 22, 1127-1134 (1987).

7. H. Tan and T. J. Ahrens, J. Mater. Res. 3, 1010-1020 (1988).

8. A. Sawaoka and T. Akashi, in Shock Waves in Condensed Matter-1987, edited by S. C. Schmidt and N. C. Holmes (NorthHolland Physics Publishing, Amsterdam, The Netherlands, 1988), pp. 423-425.

9. JANAF Thermodynamical Tables, edited by M.W. Chase, Jr., C. A. Davies, J. R. Downey, Jr., D. J. Frurip, R. A. McDonald, and A. N. Syverud (American Chemical Society and the American Institute of Physics for the National Bureau of Standards, 1985), pp. 1563,634 .

10. G. T. Gray, Metall. Trans. 20A, June, 1989.

11. LASL Shock Hugoniot Data, edited by S. P. Marsh (University of California, Berkeley, CA, 1980), pp. 328, 249.

12. R. W. Heine, C. R. Loper, Jr., and P. C. Rosenthal, Principles of Metal Casting (McGraw-Hill Book Company, New York, 1967), pp. 178-209.

13. Handbook of Fillers and Reinforcements for Plastics, edited by Harry S. Katz and John V. Milewski (Van Nostrand Reinhold Company, New York, 1978), p. 66. 
14. M. N. Pavlovskii, Sov. Phys. Solid State 13, $741-742$ (1971).

15. Tateho Chemical Industries Co., Ltd., technical data, 1988.

16. T. Soma, A. Sawaoka, and S. Saito, in Proc. Fourth Int. Conf. on High Pressure-1974, Special Issue of the Rev. of Phys. Chem. Jpn., edited by J. Osugi (Kawakita, Kyoto, Japan, 1975), pp. 446-453.

17. Lange's Handbook of Chemistry, edited by J. A. Dean (McGrawHill, Inc., New York, 1985), p. 3-2, 9-63, 9-137, 4-123.

18. E. Knittle, R.M. Wentzcovitch, R. Jeanloz, and M. L. Cohen, Nature 337, 349-352 (1989).

19. J. A. Van Vechten, Phys. Rev. B 7, 1479-1507 (1973).

20. R. Kinslow, High Velocity Impact Phenomena (Academic Press, Inc., New York, 1970), p. 549, 551, 374.

21. Derived from T. Mashimo's data in Shock Waves in Condensed Matter-1987, edited by S. C. Schmidt and N. C. Holmes (NorthHolland Physics Publishing, Amsterdam, The Netherlands, 1988), pp. 289-292.

22. M. B. Boslough, A Thermodynamical Model for Shock-Induced Chemical Reactions in Porous Solids: Analogs and Contrasts to Detonation, in Proc. 9th Symp. (Int.) on Detonation-1989.

23. J. M. Hill and J. N. Dewynne, Heat Conduction (Blackwell Scientific Publications, 1987), p. 197.

24. J.H. Lienhard, A Heat Transfer Text Book (Prentice-Hall, Inc., Englewood Cliffs, NJ, 1981), p. 492.

25. P. Schwarzkopf and R. Kieffer, Cemented Carbides (The Macmillan Company, New York, 1960), p. 67.

26. T.J. Ahrens, in Methods of Experimental Physics (Academic Press, New York, 1987), Vol. 24, Part A, pp. 185-234.

27. T.J. Ahrens, D. Kostka, P. Kasiraj, and T. Vreeland, Jr., in Rapid Solidification Processing Principles and Technologies, III, Proc. 3rd Conf. on Rapid Solidification Processing, edited by R. Mehrabian (U.S. National Bureau of Standards, Gaithersburg, MD, 1982), pp. 672-677.

28. W. H. Gourdin, J. Appl. Phys. 55, 172-181 (1984).

29. R. B. Schwarz, P. Kasiraj. T. Vreeland, Jr., and T. J. Ahrens, Acta Metall. 32, 1243 (1984).

30. R. A. Robie, B.S. Hemingway, and J. R. Fisher, Thermodynamic Properties of Minerals and Related Substances at $298.15 \mathrm{~K}$ and 1 bar $\left(10^{5}\right.$ pascals) Pressure and at Higher Temperatures (Geological Survey Bulletin 1452, 1978), p. 41.

31. John V. Milewski, A Study of the Packing of Fibers and Spheres, Ph.D. Thesis, Rutgers University (1973).

32. P. Kumar and R. J. Clifton, J. Appl. Phys. 48, 4850 (1977).

33. R. L. Rabie, J.E. Vorthman, and J. K. Dienes, Shock Waves in Condensed Matter-1983, edited by J R. Asay, R. A. Graham, and G.K. Straub (Elsevier Science Publisher B.V., 1984), pp. 199-202.

34. A. Mutz and T. Vreeland, Jr., Several Techniques for OneDimensional Strain Consolidation of Multiple Cavities, in Proc. Int. Conf. On High Strain Phenomena in Materials, edited by L. E. Murr, M. Meyers, and K. P. Staudhammer (1991).

\section{APPENDIX}

\section{A. Shock pressure $P_{H}$}

The impedance match technique ${ }^{26}$ was used to calculate the shock pressure in the sample from the measured flyer velocity and the sample Hugoniot estimated below.

From the Grüneisen equation of state, we can get the porous Hugoniot on the P-V plane (see Fig. A) as

$$
P_{H}=\frac{P_{d}\left(\frac{V_{0 d}-V_{d}}{2}-\frac{V_{d}}{\gamma}\right)}{\frac{V_{00}-V_{d}}{2}-\frac{V_{d}}{\gamma}}
$$

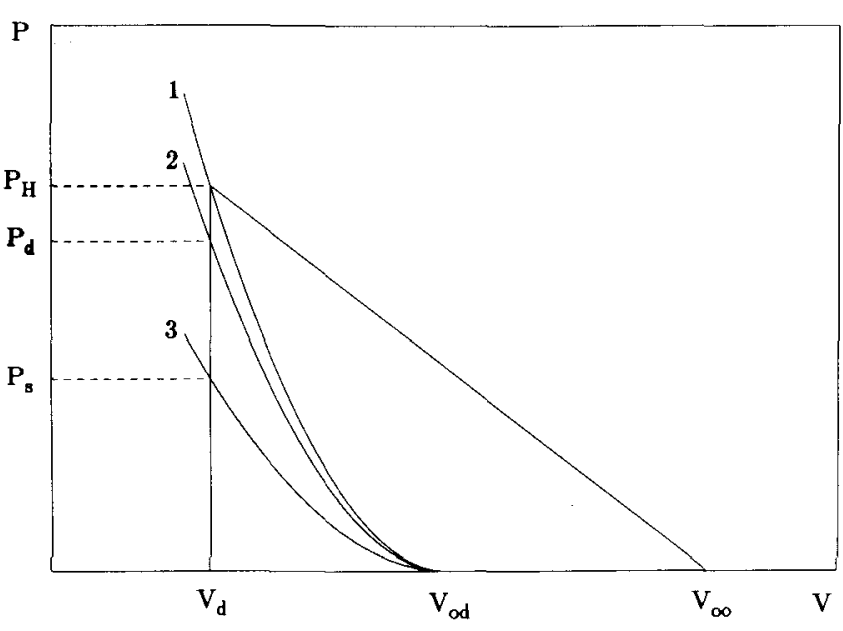

FIG. A. P-V plane. Curves 1,2 , and 3 are porous Hugoniot, known Hugoniot centered at $V_{0 d}$, and adiabat, respectively.

in which $V / \gamma=$ constant is assumed.

With the porous Hugoniot obtained from Eq. (A1), the mixture Hugoniot is obtained on the basis of volume additivity at constant pressure. ${ }^{20}$

For convenience of calculation of the shock pressure, we use the shock relations

$$
\begin{gathered}
U_{s}=V_{00}\left[P_{H} /\left(V_{00}-V_{d}\right)\right]^{1 / 2} \\
U_{p}=\left[P_{H}\left(V_{00}-V_{d}\right)\right]^{1 / 2}
\end{gathered}
$$

to obtain the linear relation $U_{s}=C_{0}+S U_{p}$ (Ref. 26).

The Hugoniot data used for c-BN, diamond, and $\mathrm{SiC}$ are from Refs. 11, 14, and 20, respectively.

\section{B. Calculation of continuum shock temperature $T_{H}$}

The continuum shock temperature $T_{H}$ of each constituent is calculated by the method of Ref. 26 .

$$
\int_{T_{s}}^{T_{H}} C_{v} d T=E_{H}-E_{s}
$$

where $C_{v}$ is the Debye specific heat. The Hugoniot energy and isentropic energy are

$$
\begin{gathered}
E_{H}=\frac{1}{2} P_{H}\left(V_{00}-V\right) \\
E_{s}=-\int_{V_{0 d}}^{V} P_{s} d V
\end{gathered}
$$

The isentropic pressure $P_{s}$ and temperature $T_{s}$ are

$$
\begin{gathered}
P_{s}=-\rho_{0} C_{0}^{2} \exp (\gamma \eta) \int_{0}^{\eta}[(\gamma-S) x-1] / \\
{\left[\exp (\gamma x)(1-S x)^{3}\right] d x}
\end{gathered}
$$

$$
T_{s}=T_{0} e^{\gamma \eta}
$$

where $\eta=1-V / V_{0}$. 


\section{Calculation of the post-shock temperature $T_{p}$}

Assuming each constituent release along its Hugoniot curve to $V_{0 d}$, the post-shock temperature $T_{p}$ is given by the following equations:

$$
\begin{gathered}
\int_{T_{0}}^{T_{p}} C_{v} d T=\frac{1}{2} P_{H}\left(V_{00}-V_{H}\right)-\int_{V_{H}}^{V_{0 d}} P_{H} d V \\
P_{H}=C_{0}^{2} \eta /\left[V_{0 d}(1-S \eta)^{2}\right]
\end{gathered}
$$

\section{Melting fraction $L$}

The formula used to calculate melt fraction is ${ }^{27-29}$

$$
L \leqslant \frac{P_{H}\left(V_{00}-V_{0 d}\right)}{2\left[C_{p}\left(T_{m}-T_{0}\right)+H_{m}\right]}
$$

where $C_{p}$ is the specific heat, and $T_{m}$ and $H_{m}$ are the melting point and latent heat of fusion, respectively. 